\title{
Haftung für Persönlichkeitsrechtsverletzungen durch Künstliche Intelligenz
}

\section{Inhaltsverzeichnis}

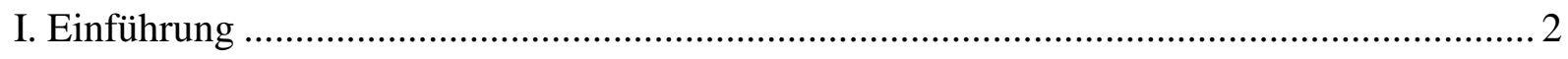

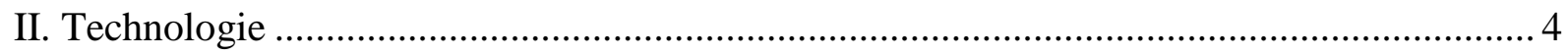

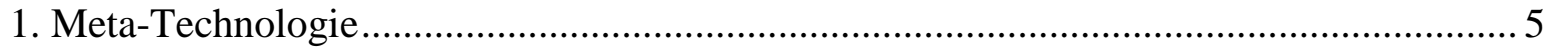

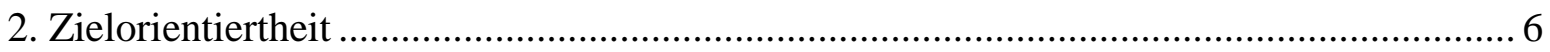

3. Autonome Entscheidungen in einer komplexen Situation ......................................... 6

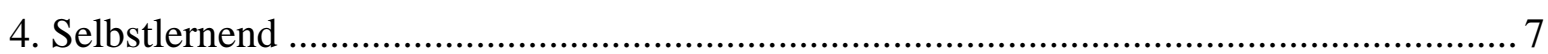

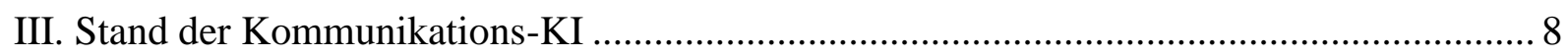

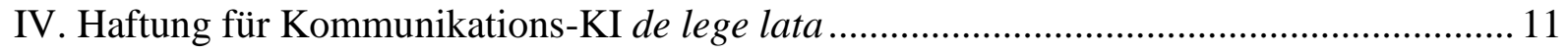

1. Gefährdungshaftung und Haftung für vermutetes Verschulden .................................... 11

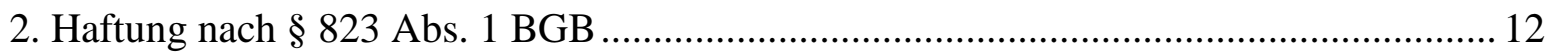

a) Beeinträchtigung eines Persönlichkeitsrechts: Auslegung der Äußerung einer KI ...... 12

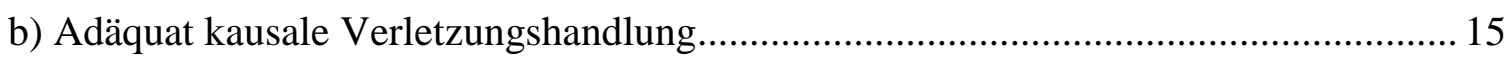

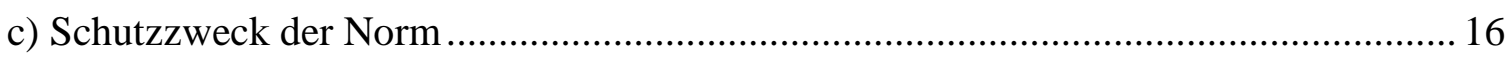

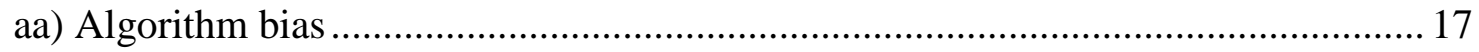

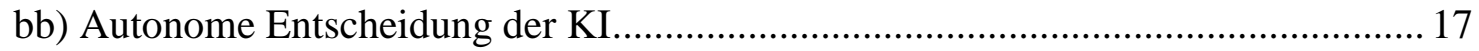

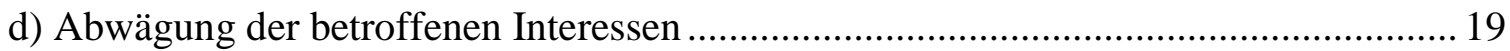

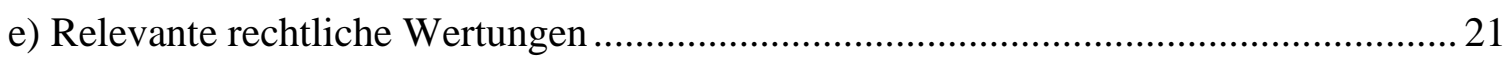

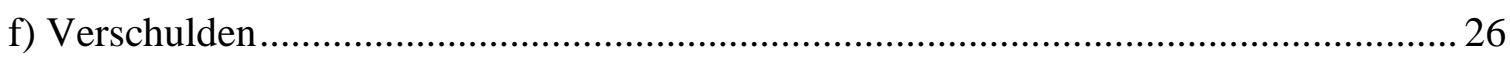

3. Haftung nach $\S 823$ Abs. 2 BGB i.V.m. $\S \S 185$ ff. StGB ........................................... 28

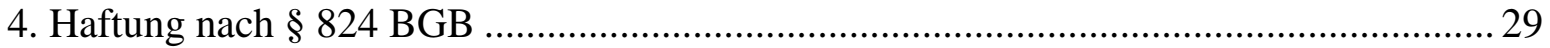

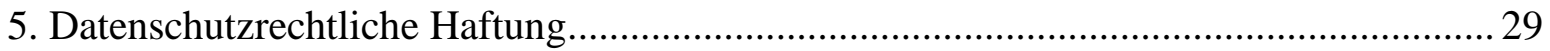

V. Haftung für Kommunikations-KI de lege ferenda ............................................................... 32

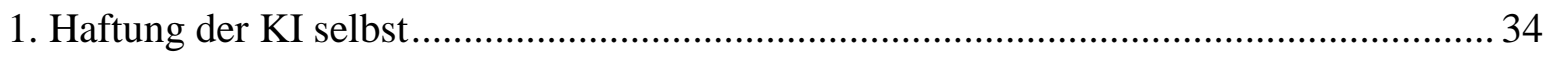

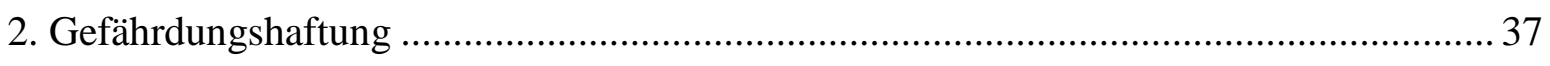

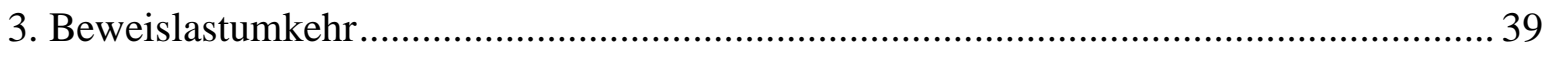

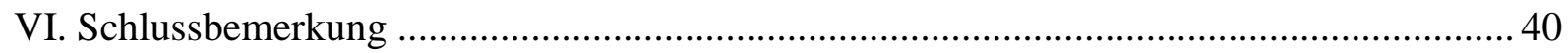




\section{Einführung}

$\mathrm{Zu}$ den großen, bislang nicht bewältigten Herausforderungen für das moderne Medien- und sonstige Kommunikationsrecht gehört die Haftung für Informationen, die durch Systeme Künstlicher Intelligenz (KI) ${ }^{1}$ generiert und gegenüber Menschen kommuniziert werden. Beispielhaft zu nennen sind etwa die Ergänzungsfunktion von Internet-Suchmaschinen, Chatbots wie Microsofts Tay und Xiaoice sowie Social Bots, die sich an Diskussionen in Sozialen Netzwerken beteiligen. ${ }^{2}$

In der rechtswissenschaftlichen Forschung widmen sich viele Beiträge verdienstvoll den grundsätzlichen Fragen der KI als solcher. ${ }^{3}$ Dabei vernachlässigen sie aber häufig die Besonderheiten einzelner Formen sog. schwacher KI (zur Terminologie sogleich), wozu auch die Kommunikations-KI zählt. Als ein extremes Beispiel hierfür stehen die Empfehlungen des Europäischen Parlaments an die Kommission zu zivilrechtlichen Regelungen im Bereich Robotik. ${ }^{4}$ Darin plädiert das Europäische Parlament für eine Gefährdungshaftung bzw. einen „Risikomanagementansatz“5 und langfristig für einen speziellen rechtlichen Status für Roboter als „elektronische Person“.6 Jedoch behandelt das Europäische Parlament verschiedenste Erscheinungsformen der Robotik und der KI - starke und schwache KI, autonome und automatische Systeme - als monolithische Erscheinung „Robotik“. Auf eine

* Assistant Professor for EU Law and Institutions an der Universität Leiden. Dem Beitrag liegt ein Vortrag zugrunde, den der Verfasser am 10. April 2018 an der Philipps-Universität Marburg hielt.

1 Der Begriff Artificial Intelligence (AI) geht zurück auf eine Konferenz, die der Informatiker John McCarthy 1956 organisierte (Russell/Norvig, Artificial Intelligence, 3. Aufl. 2016, S. 17). Kritisch zu dem Begriff Stiemerling, CR 2015, 762.

2 Zu Einzelheiten der Kommunikations-KI unter III.

3 Z.B. Beck, JR 2009, 225; Müller-Hengstenberg/Kirn, MMR 2014, 307; Horner/Kaulartz, CR 2016, 7; Nürnberger/Budiel, DuD 2016, 503; Gleß/Weigend, ZStW 126 (2014), 561; Hanisch, in: Hilgendorf (Hrsg.), Robotik im Kontext von Recht und Moral, 2014, 27; Spindler, CR 2015, 766; Grützmacher, CR 2016, 695; Spiecker gen. Döhmann, CR 2016, 698; Janal, in: Gless/Seelmann (Hrsg.), Intelligente Agenten und das Recht, 2016, 141 ff.; Zech, in: Gless/Seelmann (Hrsg.), Intelligente Agenten und das Recht, 2016, 163 ff.; Rempe, InTer 2016, 17; Keßler, MMR 2017, 589; Schaub, JZ 2017, 342; Denga, CR 2018, 69.

4 Entschließung des Europäischen Parlaments vom 16. Februar 2017 mit Empfehlungen an die Kommission zu zivilrechtlichen Regelungen im Bereich Robotik (2015/2103(INL)), Tz. 53.

5 Mit dem Risikomanagementansatz wird „nicht die Person, ,die fahrlässig gehandelt hat“, als persönlich haftend in den Mittelpunkt gestellt [...], sondern die Person, die imstande ist, unter bestimmten Umständen die Risiken zu minimieren und die negativen Auswirkungen zu bewältigen“ (Entschließung des Europäischen Parlaments vom 16. Februar 2017 mit Empfehlungen an die Kommission zu zivilrechtlichen Regelungen im Bereich Robotik (2015/2103(INL)), Tz. 55).

6 Europäisches Parlament, Entwurf eines Berichts mit Empfehlungen an die Kommission vom 31.05.2016 zu zivilrechtlichen Regelungen im Bereich Robotik (2015/2103(INL)), Tz. T; Entschließung des Europäischen Parlaments vom 16. Februar 2017 mit Empfehlungen an die Kommission zu zivilrechtlichen Regelungen im Bereich Robotik (2015/2103(INL)), Tz. 59. 
Definition „des Roboters“ bzw. „der KI“ verzichtet es hingegen ganz. ${ }^{7}$ Dieser Mangel an Differenziertheit verführt zu der offenbar Hollywood-inspirierten Vision, „dass immer ausgeklügeltere Roboter, Bots, Androiden und sonstige Manifestationen Künstlicher Intelligenz (,KI“) anscheinend nur darauf warten, eine neue industrielle Revolution zu entfesseln" ${ }^{* 8}$. Mit Erleichterung stellt der Beobachter somit fest, dass sich die „Manifestationen Künstlicher Intelligenz“ nach Ansicht der Abgeordneten mit einer industriellen Revolution begnügen und nicht gleich die Weltherrschaft an sich zu reißen gedenken. Als Grundlage für eine sachgerechte, differenzierte Analyse zivilrechtlicher Haftung für bestimmte Formen schwacher KI ist die Empfehlung des Europäischen Parlaments allerdings nicht dienlich. ${ }^{9}$

Im Unterschied zu deduktiven, holistischen Ansätzen konzentriert sich dieser Beitrag auf eine bestimmte Form von KI, nämlich durch KI generierte und an Menschen kommunizierte Informationen, und er ist begrenzt auf deliktische Haftung für Persönlichkeitsrechtsverletzungen. ${ }^{10}$ Dieser induktive Ansatz beruht auf folgender Überlegung: Zwar sind allgemeine Prinzipien zur rechtlichen Bewältigung von KI notwendig, etwa die Frage, ob und inwieweit KI Rechtsfähigkeit besitzen sollte (dazu unter V. 1.). Die Erscheinungsformen der KI und ihre strategische Ziele sind aber zu heterogen, um allein aus allgemeinen Überlegungen heraus Schlussfolgerungen für den Einzelfall zu ziehen. Anders als etwa bei selbstfahrenden Autos, Medizin- oder Haushaltsrobotern geht es bei Kommunikations-KI nicht um eindeutig lokalisierbare Sachbeschädigungen oder Körperverletzungen, sondern um physisch nicht fassbare Informationen und deren häufig grenzüberschreitende Kommunikation, durch die womöglich Persönlichkeitsrechte verletzt werden. Bei Persönlichkeitsrechtsverletzungen kommen daher Unterlassung, Gegenrede, Gegendarstellung, Berichtigung und Widerruf besondere Bedeutung $\mathrm{zu}$; Unfälle und medizinische Behandlungsfehler hingegen lösen zumeist unmittelbar Schadensersatzansprüche aus. Ferner ist die Frage, ob eine Persönlichkeitsrechtsverletzung durch eine KI rechtswidrig ist, durch Abwägung der widerstreitenden Grundrechte zu

7 Entschließung des Europäischen Parlaments vom 16. Februar 2017 mit Empfehlungen an die Kommission zu zivilrechtlichen Regelungen im Bereich Robotik (2015/2103(INL)), Tz. C. Anders noch der Rechtsausschuss des Europäischen Parlaments in dem Berichtsentwurf vom 31.05.2016, Tz. 1 sowie Nevejans, European Civil Law Rules in Robotics, Study for the JURI Committee, PE 571.379, 2016, S. 8 ff.

8 Entschließung des Europäischen Parlaments vom 16. Februar 2017 mit Empfehlungen an die Kommission zu zivilrechtlichen Regelungen im Bereich Robotik (2015/2103(INL)), Tz. B.

9 Kritisch auch Lohmann, ZRP 2017, 168, 171; Denga, CR 2018, 69, 76 f.

10 Fragen der Vertragsrechts, der IT-Sicherheit, des Strafrechts und der Regulierung bleiben daher ausgeklammert. 
beantworten. Eine solche Grundrechtssensibilität ist bei physischen Unfällen demgegenüber regelmäßig nicht gegeben. Während daher beispielsweise die Produkthaftung für einige Formen schwacher KI, etwa autonome Autos, ein nützliches Rechtsinstrument zu sein scheint, ist sie für Kommunikations-KI abzulehnen (dazu unter V. 2.). Auch stellen sich bei Kommunikations-KI besondere Probleme im Bereich des Datenschutzes, die sich etwa bei Haushaltsrobotern in dieser Form nicht stellen (siehe dazu unter IV. 5.).

Dieser Beitrag entwickelt zunächst eine Arbeitsdefinition des Begriffs der Künstlichen Intelligenz im Allgemeinen (dazu II.) und stellt daraufhin den Untersuchungsgegenstand der Kommunikations-KI im Besonderen (dazu III.) dar. Es wird dargelegt, dass die bestehende Rechtsdogmatik grundsätzlich gut gerüstet ist, um möglichen Persönlichkeitsrechtsverletzungen durch Kommunikations-KI zu begegnen (dazu IV.). Zwar bedarf es daher keiner grundlegenden Veränderungen des Rechts; gleichwohl ist eine Umkehr der Beweislast rechtspolitisch wünschenswert (dazu V.).

\section{Technologie}

Die rechtliche Bewältigung eines Phänomens beginnt mit der Bestimmung seines Gegenstandes. Nichts anderes gilt für Künstliche Intelligenz. Zwar trifft es zu, dass sich der Begriff der KI nicht ein für alle Mal abschließend festlegen lässt, im Gegenteil: Eine zu starre Begriffsbestimmung schadet der juristischen Erfassung mehr, als dass es ihr nützt. ${ }^{11}$ Gleichwohl bedarf es zumindest einer „Arbeitsdefinition“ (working definition), welche die konzeptionelle Grundlage eines Gedankengerüsts bildet. Diese Arbeitsdefinition muss nicht notwendig mit der Definition von KI übereinstimmen, wie sie in der Informatik verwendet wird; eine unumstrittene Definition existiert auch dort ohnehin nicht. ${ }^{12}$ Sie sollte jedoch zumindest die deskriptiven Faktoren aufnehmen, über die bei der Bestimmung des Begriffs der KI weitgehende Einigkeit besteht und die für die juristische Bewältigung notwendig sind. Bereits die Entwicklung auch nur einer Arbeitsdefinition von KI für rechtswissenschaftliche Zwecke stellt indessen eine Herausforderung dar, denn sie stößt an die Grenzen der Leistungsfähigkeit menschlicher Sprache. Zahlreiche Begriffe des KI-Diskurses bauen auf Konzepten auf, die mit genuin menschlichen Eigenschaften und Fähigkeiten assoziiert werden. Hierzu gehört bereits das namensgebende Wort „Intelligenz“, außerdem etwa „lernen“, „Wissen“, „Bewusstsein“, „Handeln“ u.v.m. Der nachfolgend entwickelten

\footnotetext{
11 Vgl. Schirmer, JZ 2016, 660.

12 Gleß/Weigend, ZStW 126 (2014), 561, 562; Stiemerling, CR 2015, 762.
} 
Arbeitsdefinition ist daher vorauszuschicken, dass keiner der Begriffe, die darin verwendet werden, als notwendig anthropologisch zu verstehen ist.

Im Sinne dieser Untersuchung ist „Künstliche Intelligenz“

1. eine Meta-Technologie, die

2. fähig ist, ein strategisches Ziel zu erreichen und dafür

3. in einer komplexen Situation autonome Entscheidungen trifft und

4. selbstlernend ist.

\section{Meta-Technologie}

In der Informatik wird unterschieden zwischen sog. „starker“ und „schwacher“ KI. Starke KI (strong AI oder human-level AI) besitzt die Fähigkeit, jegliche kognitive Aufgabe zumindest ebenso gut zu lösen wie Menschen. ${ }^{13}$ Starke KI ist derzeit noch nicht existent; ob und wann es eine solche superhumane KI geben überhaupt wird, ist Gegenstand intensiver Debatten. ${ }^{14}$ Für die Zwecke dieses Beitrages kann starke KI daher vorläufig ausgeklammert bleiben.

Derzeit existierende Formen von KI sind allesamt sog. schwache KI (narrow AI). Diese sind lediglich dazu fähig, in einem bestimmten und begrenzten Anwendungsbereich - zumeist auf der Grundlage großer, häufig vernetzter Datenbestände („Big Data“) - bestimmte Ziele zu erreichen, z.B. ein Auto zu fahren oder Schach zu spielen. ${ }^{15}$ Schwache KI ist daher keine Technik, mit der nur eine bestimmte Aufgabe bewältigt werden kann, sondern eine MetaTechnologie, die eine Vielzahl von Anwendungen ermöglicht. Hierzu gehören etwa Vertragsschlüsse ${ }^{16}$, Investmententscheidungen ${ }^{17}$, Rechtsberatung und Rechtsdurchsetzung („Legal Tech“) ${ }^{18}$, selbstfahrende Autos ${ }^{19}$, militärische Anwendungen, Haushaltsdienste, medizinische Versorgung, Pflege und eben Kommunikation.

13 Tegmark, Life 3.0, 2017, S. 52; Russell/Norvig, Artificial Intelligence, 3. Aufl. 2016, S. 27; Conrad, DuD 2017,740 .

14 Siehe etwa Tegmark, Life 3.0, 2017, S. 30 ff.; Russell/Norvig, Artificial Intelligence, 3. Aufl. 2016, S. 1020 ff.; Stiemerling, CR 2015, 762, 765; Frankfurter Allgemeine Zeitung vom 15. März 2018, „Stephen Hawking“.

15 Tegmark, Life 3.0, 2017, S. 39.

16 Dazu Specht/Herold, MMR 2018, 40 ff.; Müller-Hengstenberg/Kirn, MMR 2014, 307, 308 f.

17 Dazu Möslein/Lordt, ZIP 38 (2017), 793; Ji, Columbia Law Review 117 (2017), 1543.

18 Dazu Frese, NJW 2015, 2090; Fries, NJW 2016, 2860, 2861 ff.

19 Dazu Spindler, CR 2015, 766; Fleck/Thomas, NJOZ 2015, 1393; Lutz, NJW 2015, 119; Jourdan/Matschi, NZV 2015, 26; Weisser/Färber, MMR 2015, 506; Boeglin, Yale Journal of Law and Technology 17 (2015), 171; Kohler/Colbert-Taylor, Santa Clara High Technology Law Journal 31 (2015), 99; Armbrüster, in: Gless/Seelmann (Hrsg.), Intelligente Agenten und das Recht, 2016, 205; Gless, in: Gless/Seelmann (Hrsg.), Intelligente Agenten und das Recht, 2016, 225. 


\section{Zielorientiertheit}

$\mathrm{KI}$ ist zielorientiert und fähig, dieses Ziel zu erreichen. ${ }^{20}$ Welches Ziel die KI verfolgt, bestimmt sich nach ihrer Programmierung (dazu soeben unter 1.). Die Zielsetzung kann etwa darin bestehen, ein Muster (z.B. von Bildern oder von Sprache) oder Bedeutungszusammenhänge zu erkennen, Schlussfolgerungen zu ziehen und zielorientiert zu handeln. ${ }^{21}$ Ziel eines Schachcomputers ist es etwa, ein Schachspiel zu gewinnen, Ziel eines selbstfahrenden Autos ist es, die Insassen möglichst schnell und möglichst sicher von A nach B zu bringen.

\section{Autonome Entscheidungen in einer komplexen Situation}

Eine KI trifft in einer komplexen Situation autonome Entscheidungen. ${ }^{22}$ Komplexität ist dann gegeben, wenn nach Ingangsetzung der KI unvorhersehbare Informationen auf die KI einwirken, auf die die KI auf der Grundlage der ihr zur Verfügung stehenden Datensätze reagiert. Bei Spiele-KIs etwa sind diese Faktoren die Spielzüge des Gegners, bei selbstfahrenden Autos das Verhalten der anderen Verkehrsteilnehmer, und bei den hier relevanten Kommunikations-KI sind dies Äußerungen von Gesprächspartnern. Komplexität ist nicht zu verwechseln mit Kompliziertheit. Ein Taschenrechner etwa bewältigt komplizierte Rechenaufgaben, die für einen Menschen - zumindest in dieser Geschwindigkeit - nicht zu lösen sind. Gleichwohl ist ein Taschenrechner nicht auf die Bewältigung komplexer Probleme angelegt, da nach der Ingangsetzung der Rechenoperation (d.h. dem Drücken der Gleichtaste) keine weiteren Informationen auf den Taschenrechner einwirken.

Die Entscheidung der KI ist dann als ,autonom“ zu bezeichnen, wenn die konkrete Reaktion des Programms nicht vorgegeben ist, selbst der Programmierer also diese konkrete Entscheidung nicht vorhersehen konnte. ${ }^{23}$ Ist die konkrete Reaktion des Programms bereits im Algorithmus determiniert, so ist von einem ,automatischen“ System zu sprechen. ${ }^{24}$ So handelt

20 Dieses Kriterium steht im Zentrum der KI-Definition von Tegmark, Life 3.0, 2017, S. 50.

21 Stiemerling, CR 2015, 762.

22 Vgl. Nürnberger/Budiel, DuD 2016, 503, 504; Grützmacher, CR 2016, 695, 696; Taeger, NJW 2016, 3764, 3765; Spiecker gen. Döhmann, CR 2016, 698, 701.

23 Vgl. Stiemerling, CR 2015, 762, 764; Müller-Hengstenberg/Kirn, MMR 2014, 307, 309; Gleß/Weigend, ZStW 126 (2014), 561; Spindler, CR 2015, 766; Spiecker gen. Döhmann, CR 2016, 698, 701; Denga, CR 2018, 69, 70. Hanisch, in: Hilgendorf (Hrsg.), Robotik im Kontext von Recht und Moral, 2014, 27, 53 spricht positiv, in der Sache aber gleichbedeutend von einem „Entscheidungsspielraum“ des Roboters; wegen der anthropologischen Konnotation dieses Begriffs wird hier aber die negative Definition bevorzugt.

24 Siehe DIN 19233 zu „Automat“: „Ein selbsttätig arbeitendes künstliches System, dessen Verhalten entweder schrittweise durch vorgegebene Entscheidungsregeln oder zeitkontinuierlich nach festgelegten Beziehungen bestimmt wird und dessen Ausgangsgrößen aus seinen Eingangs- und Zustandsgrößen gebildet werden." 
es sich bei den gegenwärtig zugelassenen Fahrassistenzsystemen um automatische (oder automatisierte) Systeme. ${ }^{25}$ Ein autonomes Fahrsystem, welches ein Kraftfahrzeug selbständig führt, ist auf Deutschlands Straßen derzeit noch nicht zugelassen. ${ }^{26}$ „Autonomie“ ist indessen kein binärer Begriff; stattdessen ist nach verschiedenen Graden an Eigenständigkeit einer Entscheidung zu unterscheiden. ${ }^{27}$

\section{Selbstlernend}

KI beruht auf selbstlernenden Algorithmen mittels tiefer neuronaler Netze, sog. deep learning. ${ }^{28}$ Wie eingangs unterstrichen, ist der Begriff „lernend“ hier nicht als anthropologisches Konzept zu verstehen. „Lernend“ meint hier, dass die KI auf der Grundlage aufgenommener Informationen und eigener „Fehler“ Muster erkennt und eine Handlungsoption wählt, die die Erreichung des strategischen Ziels (dazu 2.) wahrscheinlicher macht. Unter „Fehler“ ist hier eine Handlung zu verstehen, die nicht optimal zur Erreichung des strategischen Ziels beiträgt. ${ }^{29}$ Es ist dieses Kriterium des „Lernens aus eigener Erfahrung“, welches KI - nach der hier vorgeschlagenen Arbeitsdefinition ${ }^{30}$ - von anderen autonomen Systemen unterscheidet. Diese Abgrenzung lässt sich am Unterschied zwischen „AlphaGo“ und „Deep Blue“ verdeutlichen. 1996 und 1997 gelang es dem von IBM entwickelten Schachcomputer Deep Blue, den amtierenden Schachweltmeister Garri Kasparow zu schlagen. Deep Blues Spielstärke beruhte vor allem auf der Verarbeitung einer

25 Siehe §§ 1a und 1b StVG; Jourdan/Matschi, NZV 2015, 26, 27; Armbrüster, in: Gless/Seelmann (Hrsg.), Intelligente Agenten und das Recht, 2016, 205 ff.

26 Fleck/Thomas, NJOZ 2015, 1393, 1395; Weisser/Färber, MMR 2015, 506, 511; vgl. § 2 Abs. 4 StVG: „Geeignet zum Führen von Kraftfahrzeugen ist“" nur derjenige, der „die notwendigen körperlichen und geistigen Anforderungen erfüllt" (Kursivdruck durch Verf.). Missverständlich daher Lutz, NJW 2015, 119, der die Begriffe „autonom“ und „automatisiert" synonym verwendet.

27 Boden, in: dies. (Hrsg.), The Philosophy of Artificial Life, 1996, S. 95; Ball/Callaghan, Explorations of autonomy: an investigation of adjustable autonomy in intelligent environments, 8th International Conference on Intelligent Environments (IE), 2012, 114; Schulz, Verantwortlichkeit bei autonom agierenden Systemen, 2015, S. 44 f.; Reichwald/Pfisterer, CR 2016, 208, 210.

28 Zur Technologie des deep learning Hinton/Osindero/Teh, Neural Computation 18 (2006), 1527; LeCun/Bengio/Hinton, Nature 521 (2015), 436; Hinton, Trends in Cognitive Sciences 11 (2007), 428; Schmidhuber, Neural Networks 61 (2015), 85.

29 Beispielhaft sei hier die KI genannt, die das Atari Spiel „Breakout“ spielte (Tegmark, Life 3.0, 2017, S. 84 f.): Bei diesem Spiel steuert der Spieler eine kleine Plattform, um damit eine Kugel gegen eine Wand prallen zu lassen. Bei jedem Aufschlag gegen die Wand löst sich ein „Stein“ in der Wand auf, was dem Spieler Punkte einbringt. Nach einigen recht unkoordiniert wirkenden Bewegungen ,erkannte“ die KI, dass sie den Ball treffen muss, um Punkte zu erzielen (d.h. um ihr strategisches Ziel zu erreichen) und entwickelte schließlich sogar eine Strategie, über die sie mit wenig Aufwand die Höchstpunktzahl erzielte.

30 Ähnlich Gleß/Weigend, ZStW 126 (2014), 561, 563; Spindler, CR 2015, 766; Reichwald/Pfisterer, CR 2016, 208, 212; Nürnberger/Budiel, DuD 2016, 503; Taeger, NJW 2016, 3764, 3765; Spiecker gen. Döhmann, CR 2016, 698, 700; Volkmann, MMR 2018, 58, 59; anders z.B. Specht/Herold, MMR 2018, 40, 41, die ,autonom“ und „selbstlernend“" gleichsetzen. 
umfangreichen Spiele-Datenbank und seiner Rechenleistung; seine Software berechnete zwischen 100 und 200 Millionen Stellungen pro Sekunde. ${ }^{31}$ Allerdings nahmen die Programmierer von Deep Blue zwischen den Partien Änderungen an der Software vor, um Fehler zu beseitigen und Deep Blues Spiel zu verbessern. ${ }^{32}$ Deep Blue war daher zwar ein autonomes System; seine Programmierer konnten nicht vorhersehen, welche konkreten Züge Deep Blue in der komplexen Situation des Schachspiels vornehmen würde. Deep Blue war aber kein selbstlernendes System. ${ }^{33}$ Vereinfacht gesagt war Deep Blue nach heutiger Diktion „nur“ ein reines Big Data-System, aber noch keine KI. Im Unterschied dazu beruht das Computerprogramm AlphaGo, welches zwischen 2015 und 2017 mehrere der besten Spieler der Welt im Brettspiel „Go“ besiegte, auch auf maschinellem Lernen und verbesserte so sein eigenes Spiel. ${ }^{34}$ Ein solches intelligentes System sind beispielweise auch Googles Suchergänzungsfunktion und Amazons „Empfehlungen“ zum Kauf weiterer Produkte. ${ }^{35}$

Gemeinsam mit dem Kriterium der Autonomie stellt das Kriterium des Selbstlernens die zentrale Herausforderung der KI für die Rechtswissenschaft dar, da im Zeitpunkt der Programmierung des Algorithmus nicht vorhersehbar ist, wie sich die KI in einer bestimmten Situation verhalten wird. ${ }^{36}$ Es wird daher zu prüfen sein, inwieweit das „Verhalten“ einer KI ihrem Verwender zugerechnet werden kann (dazu unter IV. 2. c)).

\section{Stand der Kommunikations-KI}

Sogenannte fortgeschrittene natürlichsprachliche Generierung (Advanced natural language generation, Advanced $N L G$ ) ist inzwischen so weit entwickelt, dass sie Daten auf eine Weise in Narrative verwandeln kann, dass menschliche und maschinell generierte Texte kaum noch voneinander unterscheidbar sind ${ }^{37}$ Beispiele für Kommunikations-KI sind etwa sog. virtuelle Assistenten (z.B. Apples „Siri“ und Amazons „Alexa“), Ergänzungsfunktionen bei Suchmaschinen $^{38}$ und Übersetzungen (z.B. Google translate). Von besonderem

31 Ausführlich Campbell/Hoane Jr./Hsu, Deep Blue, 2001, abrufbar unter http://sjeng.org/ftp/deepblue.pdf.

32 So die Angaben bei https://de.wikipedia.org/wiki/Deep_Blue.

33 Vgl. Tegmark, Life 3.0, 2017, S. 78. Dies konzediert auch IBM selbst: https://www.research.ibm.com/deepblue/meet/html/d.2.html.

34 Decker, in: Gless/Seelmann (Hrsg.), Intelligente Agenten und das Recht, 2016, 23, 35 ff.

35 Gleß/Weigend, ZStW 126 (2014), 561, $563 \mathrm{f}$.

36 Beck, JR 2009, 225, 226; Gleß/Weigend, ZStW 126 (2014), 561, 564 f.

37 Dörr, Digital Journalism 4 (2016), 700, 701; Clerwall, Journalism Practice 8 (2014), 519.

38 Bei einer Eingabe in eine Suchmaschine präsentiert ein Algorithmus Wortkombinationen, die von anderen Nutzern zu dem fraglichen Suchbegriff am häufigsten eingegeben wurden und die sich auf den Webseiten befinden, auf die die Suchmaschine verweist. 
medienrechtlichen Interesse ist die sog. „quantitative Wende“ (quantitative turn) vom anthropogenen zum algorithmischen Journalismus. Algorithmen unterstützen Journalisten nicht mehr nur noch in ihrer Arbeit; stattdessen führen sie selbst journalistische Arbeit durch, indem sie Informationen recherchieren, redaktionell überarbeiten, veröffentlichen und/oder gezielt an bestimmte Rezipienten verbreiten. ${ }^{39}$ In der publizistischen Literatur werden hierfür verschiedene Begriffe verwendet, z.B. „Roboterjournalismus“40, „,automatischer Journalismus“441, „algorithmischer Journalismus“42, „Datenjournalismus“443 und „Computerjournalismus“444. Während diese Begriffe teilweise konzeptionelle Unterschiede ausdrücken, werden sie allesamt unter einem Oberbegriff zusammengefasst: die „quantitative Wende des Journalismus“. ${ }^{45}$ Diese neue Form des Journalismus betritt das Mediengeschäft durch zwei Eingänge: Zum einen ermöglicht sie Internet-Diensteanbietern, etwa Sozialen Netzwerken, in das Informationsgeschäft einzusteigen. ${ }^{46}$ Zum anderen ist sie inzwischen ein fester Bestandteil auch von traditionellen Medienorganisationen. ${ }^{47}$ So berichtete die Washington Post, deren Eigentümer nicht zufällig Amazon-Gründer Jeff Bezos ist, über die Olympischen Sommerspiele 2016 mit ihrem KI-System „Heliograf“. Es steht zu erwarten, dass KI die Medienlandschaft nachhaltig verändern wird. ${ }^{48}$

Kommunikations-KI ist zumeist - wenn auch nicht notwendig - Big Data-basiert. Ein gegenüber Menschen uneinholbarer Vorsprung von Kommunikations-KI besteht somit in den Datenbanken (z.B. Wikipedia), auf die KI je nach Grad der Vernetzung zugreifen kann. Die Möglichkeiten der Kommunikations-KI gehen jedoch über faktenbasierte - und zumeist einseitige - Kommunikation hinaus. Ein Beispiel hierfür sind sog. Chatbots, die jeweils mit

39 Rosenbaum, Curation Nation, 2011; Bakker, Journalism Practice 6 (2012), 627; Van Dalen, Journalism Practice 6 (2012), 648; Howard, The Art and Science of Data-driven Journalism, 2014; Diakopoulos, Digital Journalism 3 (2015), 398; Broussard, Digital Journalism 3 (2015), 814; Primo/Zago, Digital Journalism 3 (2015), 38; Haarkötter, Tendenz 2017, 24; s.a. Medientage München, Special: Kollege Roboter - Wenn Künstliche Intelligenz auf journalistische Kreativität trifft, https://medientage.de/workshop_item/kollegeroboter.

40 Clerwall, Journalism Practice 8 (2014), 519; Weberling, NJW 2018, 735.

41 Carlson, Digital Journalism 3 (2014), 416.

42 Anderson, New Media \& Society 15 (2013), 1005; Dörr, Digital Journalism 4 (2016), 700.

43 Appelgren/Nygren, Digital Journalism 2 (2014), 394; Gynnild, Journalism 15 (2014), 713; De Maeyer/Libert/Domingo/Heinderyckx/Le Cam, Digital Journalism 3 (2015), 432.

44 Cohen/Hamilton/Turner, Communications of the ACM 54 (2011), 66; Flew/Spurgeon/Daniel/Swift, Journalism Practice 6 (2012), 157; Broussard, Digital Journalism 4 (2016), 266.

45 Siehe Coddington, Digital Journalism 3 (2015), 331; Lewis, Digital Journalism 3 (2015), 321.

46 Frankfurter Allgemeine Sonntagszeitung vom 18.09.2016, „Die Rückkehr des Feudalismus“.

47 Dörr, Digital Journalism 4 (2016), 700.

48 Cappello (Hrsg.), Journalismus und Medienprivileg, IRIS Spezial, Europäische Audiovisuelle Informationsstelle, Straßburg, 2017, S. 115 f. 
nur einer Person oder einem geschlossenen Kreis von Personen kommunizieren. ${ }^{49}$ Bekannteste Chatbots sind das von dem Informatiker Joseph Weizenbaum 1966 entwickelte Programm „Eliza“, Microsofts „Tay“ und der Chatbot „Xiaoice“, den Microsoft in China betreibt. „Eliza“ parodierte psychotherapeutische Gespräche, indem das Programm Sätze der Menschen aufnahm, umformulierte und gelegentlich eine neue Frage stellte. Entgegen Weizenbaums Erwartung - und zu seinem Entsetzen - nahmen viele Menschen „Eliza“ als Gesprächspartnerin ernst und vertrauten dem Programm ihre Geheimnisse an. ${ }^{50 ~ „ T a y “ ~}$ beteiligte sich am 23. März 2016 an Konversationen auf Twitter. Twitter-Nutzer, sogenannte „Trolle“, fütterten Tay allerdings mit rassistischen und sexistischen Aussagen, die Tay dann wiederholte. Tay blieb nur 16 Stunden online, dann schaltete Microsoft das Twitter-Konto ab. ${ }^{51}$ Erfolgreicher ist Microsoft demgegenüber mit Xiaoice, einem in China aktiven Chatbot. Millionen chinesischer Jugendlicher nutzen Xiaoice, der inzwischen auch Co-Moderator einer Fernsehsendung und einer der größten „Influencer“ auf dem chinesischen Twitter-Pendant Weibo ist. ${ }^{52}$ Chatbots dienen auch einsamen Menschen in Altersheimen als Gesprächspartner. ${ }^{53}$ Schließlich schnitt eine KI von IBM im Juni 2018 mit einem beachtlichen 1:1 in einem Debattierwettbewerb ab. ${ }^{54}$

Sog. Social Bots sind autonome Computerprogramme, die in einem Sozialen Netzwerk (z.B. Twitter oder Facebook) Diskussionsbeiträge liefern und sich dabei als reale Personen ausgeben. ${ }^{55}$ Angeblich von Russland lancierte Social Bots stehen in dem Verdacht, durch Falschnachrichten und einseitige Meinungsbildung die US-Präsidentenwahlen und das EUMitgliedschaftsreferendum im Vereinigten Königreich 2016 beeinflusst zu haben.

Traditioneller Maßstab zur Feststellung der Entwicklung von Kommunikations-KI ist der sog. Turing-Test. Der Turing-Test gilt für die Maschine als „,bestanden“, wenn ein Mensch bei einem Gespräch über Tastatur und Bildschirm die Konversation mit der Maschine nicht von der mit einem Menschen unterscheiden kann. ${ }^{56}$ Gemessen am Turing-Test sind humanoide von humanen Kommunikationspartnern bisweilen nicht mehr zu unterscheiden. ${ }^{57}$ Allerdings

\footnotetext{
49 Ausführlich zu den Anwendungsfällen von Chatbots Franck/Müller-Peltzer, DSRITB 2017, 241, 243 ff.

50 Frankfurter Allgemeine Zeitung vom 18. März 2018, „Meine Freundin ist ein Computer“.

51 So die Angaben bei https://de.wikipedia.org/wiki/Tay_(Bot); https://en.wikipedia.org/wiki/Tay_(bot).

52 Frankfurter Allgemeine Zeitung vom 17. März 2018, „Computer, darf ich raus?“.

53 Frankfurter Allgemeine Zeitung vom 18. März 2018, „Meine Freundin ist ein Computer“.

54 Handelsblatt vom 22. Juni 2018, „Wenn Computer und Mensch sich ein Rededuell liefern“.

55 Dazu Milker, ZUM 2017, 216; Volkmann, MMR 2018, 58.

56 Russell/Norvig, Artificial Intelligence, 3. Aufl. 2016, S. 2 f.; Franck/Müller-Peltzer, DSRITB 2017, $241,243$.

57 Vgl. Antos, Zeitschrift für germanistische Linguistik 45 (2017), 392 ff.; Haarkötter, Tendenz 2017, $24,26$.
} 
wird der Turing-Test in der Informatik selbst kritisch hinterfragt. Tegmark weist etwa zutreffend darauf hin, dass der Turing-Test mehr auf die menschliche Leichtgläubigkeit als auf die Intelligenz der Maschine abstellt. ${ }^{58}$

Allerdings ist nicht $\mathrm{zu}$ verkennen, dass Kommunikations-KI gegenüber menschlicher Kommunikation auch erhebliche Defizite aufweist. Eine Maschine kann zwar Muster und Verhältnisse von Worten zueinander erkennen, diesen Worten aber keinen Sinn oder Bedeutung im sprachphilosophischen Sinne beimessen. ${ }^{59}$ Daher fällt es einer KI auch schwer, Ironie zu erkennen. Auch verkennt Kommunikations-KI häufig die Bedeutung von Pronomen (sog. Winograd Schema Challenge). ${ }^{60}$

\section{Haftung für Kommunikations-KI de lege lata}

Spezielle Regelungen zur Haftung von bzw. für KI bestehen derzeit weder im nationalen noch im internationalen Recht. Bevor darauf einzugehen ist, ob die Haftung für KommunikationsKI neuer Regelungen bedarf, ist zunächst zu prüfen, inwiefern die Herausforderungen mit den Regelungen und Rechtsfiguren des bestehenden Deliktsrechts bewältigt werden können. Die Arten deliktischer Haftung lassen sich in drei Stufen einteilen: Haftung für nachgewiesenes eigenes Verschulden, Haftung für vermutetes eigenes Verschulden, und Haftung ohne Verschulden (sog. Gefährdungshaftung).

\section{Gefährdungshaftung und Haftung für vermutetes Verschulden}

Eine Gefährdungshaftung für Persönlichkeitsrechtsverletzungen durch Kommunikations-KI kommt de lege lata nicht in Betracht. ${ }^{61}$ Insbesondere scheidet eine Haftung gemäß $\S 1$ Abs. 1 Satz 1 ProdHaftG aus. Die Vorschrift umfasst nur die Rechtsgutsverletzungen Tötung, Körper- und Gesundheitsverletzung sowie Sachbeschädigung, nicht aber Persönlichkeitsrechtsverletzungen. Auch handelt es sich bei einem Algorithmus nicht um eine bewegliche Sache und damit nicht um ein Produkt i.S.d. § 2 ProdHaftG, sofern er nicht auf einem Datenträger verkörpert in den Verkehr gebracht wurde.

Eine Haftung für vermutetes Verschulden scheidet zumindest dem Wortlaut der einschlägigen Regelungen nach ebenfalls aus. Insbesondere kommt $\S 831$ Abs. 1 BGB nicht in Betracht, da

58 Tegmark, Life 3.0, 2017, S. 91; kritisch auch Russell/Norvig, Artificial Intelligence, 3. Aufl. 2016, S. 3.

59 Vgl. Tegmark, Life 3.0, 2017, S. 90. Zu „Sinn“ und „Bedeutung“ Frege, Zeitschrift für Philosophie und philosophische Kritik 100 (1892), 25, 31.

60 Tegmark, Life 3.0, 2017, S. 91. Beispiel: „Die Professorin bat die Studentin zu einem Gespräch und teilte ihr mit, dass sie durchgefallen sei." Für eine KI kann es nun schwer festzustellen sein, wer durchgefallen ist.

${ }^{61} \mathrm{Zu}$ möglichen Entwicklungen de lege ferenda siehe unter V.2. 
keine willentliche Handlung der KI vorliegt, die diese zu einem Verrichtungsgehilfen i.S.d. § 831 BGB macht. ${ }^{62}$ Ferner ist eine KI keine aufsichtsbedürftige Person i.S.d. 832 BGB. Ob die Wertungen dieser Regelungen im Rahmen der Haftung nach $\S 823$ Abs. 1 BGB zu berücksichtigen sind, wird noch zu erörtern sein.

\section{Haftung nach $\S 823$ Abs. 1 BGB}

In Betracht kommt eine Haftung des Anbieters einer Kommunikations-KI für Verletzungen von Persönlichkeitsrechten, etwa Ehre, Privatheit oder dem sog. Allgemeinen Persönlichkeitsrecht, als „,sonstiges Recht“" gemäß $§ 823$ Abs. 1 BGB.

\section{a) Beeinträchtigung eines Persönlichkeitsrechts: Auslegung der Äußerung einer KI}

Ob die Äußerung einer KI ein Persönlichkeitsrecht beeinträchtigt, bestimmt sich danach, wie die Äußerung auszulegen ist. So ist zu ermitteln, ob die Äußerung als Tatsachenbehauptung oder als Werturteil zu qualifizieren ist, welcher Aussagegehalt ihr beizumessen ist und ob der so ermittelte Aussagegehalt der Wahrheit entspricht (bei Tatsachenbehauptungen) oder Schmähkritik darstellt (bei Werturteilen). Nach gefestigter Rechtsprechung ist für die Interpretation einer Aussage das Verständnis eines unbefangenen, objektiven und unvoreingenommenen Durchschnittsempfängers (Lesers, Zuschauers oder Hörers) im Zeitpunkt der Äußerung bei einer Bewertung der Aussage in ihrem Gesamtzusammenhang unter Berücksichtigung des allgemeinen Sprachgebrauchs maßstäblich. ${ }^{63}$ Abzustellen ist grundsätzlich auf einen durchschnittlichen Informationsempfänger, der mit einer Spezialmaterie nicht vertraut ist. ${ }^{64}$ Maßgeblich ist, wie der Empfänger die Äußerungen verstehen konnte, und nicht, wie er sie auffassen musste. ${ }^{65}$ Unerheblich ist demgegenüber,

62 Schulz, Verantwortlichkeit bei autonom agierenden Systemen, 2015, S. 147; Grützmacher, CR 2016, 695, 698; Schaub, JZ 2017, 342, 344.

63 BGH, Urt. v. 19.03.1957, Az.: VI ZR 263/55, NJW 1957, 1149 - Konkursmeldung; BGH, Urt. v. 20.06.1961, Az.: VI ZR 222/60, NJW 1961, 1913, 1914 - Wiedergutmachung; BGH, Urt. v. 11.03.2008, Az. VI ZR 7/07, NJW 2008, 2110 Rn. 15 - „Gen-Milch“; BVerfG, Beschl. v. 10.10.1995, Az. 1 BvR 1476/91, 1 BvR 1980/91, 1 BvR 102/92, 1 BvR 221/92, NJW 1995, 3303, 3310 - „Soldaten sind Mörder“; BVerfG, Beschl. v. 25.10.2005, Az. 1 BvR 1696/98, BVerfGE 114, 339, 348 f. - Stolpe; Vgl. auch EGMR, Lingens/Österreich [1986] Beschwerde-Nr. 9815/82 [40]; Castells/Spanien [1992] Beschwerde-Nr. 11798/85 [48]; Nikowitz und Verlagsgruppe News GmbH/Österreich [2007] Beschwerde-Nr. 5266/03 [25]; OOO 'Vesti' und Ukhov/Russland [2013] Beschwerde-Nr. 21724/03 [63].

64 BGH, Urt. v. 20.06.1961, Az.: VI ZR 222/60, NJW 1961, 1913, 1914 - Wiedergutmachung; vgl. EGMR, Růžový panter, o.s./Tschechische Republik [2012] Beschwerde-Nr. 20240/08 [31].

65 BGH, Urt. v. 20.06.1961, Az.: VI ZR 222/60, NJW 1961, 1913, 1914 - Wiedergutmachung; BGH, Urt. v. 30.05.1974, Az. VI ZR 174/72, MDR 1974, 921 - Brüning-Memoiren I. 
was der sich Äußernde tatsächlich mitteilen wollte. ${ }^{66}$ Ein Gericht braucht auch nicht ,auf entfernte, weder durch den Wortlaut noch die Umstände der Äußerung gestützte Alternativen einzugehen oder gar abstrakte Deutungsmöglichkeiten zu entwickeln, die in den konkreten Umständen keinerlei Anhaltspunkte finden.“67 Einer Äußerung darf zudem „kein Inhalt unterschoben werden“, den ihr der sich Äußernde „erkennbar nicht beilegen wollte“. ${ }^{68}$ Auch dürfen Äußerungen nicht aus ihrem Zusammenhang gelöst werden, um so zu der Annahme zu gelangen, dass die Äußerungen allein den Zweck hatten, den Betroffenen herabzusetzen. ${ }^{69}$ Die bloße Möglichkeit von Missverständnissen braucht nicht durch klärende Zusätze ausgeschlossen $\mathrm{zu}$ werden. ${ }^{70}$ Bei mehreren möglichen Interpretationen einer Äußerung ist grundsätzlich diejenige der rechtlichen Beurteilung zu Grunde zu legen, die dem Mitteilenden günstiger ist und den Verletzten weniger beeinträchtigt. ${ }^{71}$ Eine Ausnahme gilt bei Unterlassungsansprüchen; hier ist die das Persönlichkeitsrecht stärker verletzende Interpretation anzunehmen. ${ }^{72}$ Der sich Äußernde habe schließlich „die Möglichkeit, sich in der Zukunft eindeutig auszudrücken und damit zugleich klarzustellen, welcher Äußerungsinhalt der rechtlichen Prüfung einer Verletzung des Persönlichkeitsrechts zu Grunde zu legen ist“" ${ }^{73}$ Bei der Auslegung einer Äußerung sind schließlich Besonderheiten und Sachzwänge des Kommunikationsmediums zu beachten. ${ }^{74}$

66 BGH, Urt. v. 19.03.1957, Az.: VI ZR 263/55, NJW 1957, 1149 - Konkursmeldung; BGH, Urt. v. 20.06.1961, Az.: VI ZR 222/60, NJW 1961, 1913, 1914 - Wiedergutmachung; BGH, Urt. v. 08.07.1969, Az.: VI ZR 275/67 - „Kavaliersdelikt“ Rn. 21; BGH, Urt. v. 30.05.1974, Az. VI ZR 174/72, MDR 1974, 921 Brüning-Memoiren I; BVerfG, Beschl. v. 10.10.1995, Az. 1 BvR 1476/91, 1 BvR 1980/91, 1 BvR 102/92, 1 BvR 221/92, NJW 1995, 3303, 3310 - „Soldaten sind Mörder“.

67 BVerfG, Beschl. v. 10.10.1995, Az. 1 BvR 1476/91, 1 BvR 1980/91, 1 BvR 102/92, 1 BvR 221/92, NJW 1995, 3303, 3305 - „Soldaten sind Mörder“; vgl. BGH, Urt. v. 11.03.2008, Az. VI ZR 7/07, NJW 2008, 2110 Rn. 27 - „Gen-Milch“.

68 BVerfG, Beschl. v. 25.03.1992, Az. 1 BvR 514/90, BVerfGE 86, 1, 9 - „geb. Mörder, Krüppel“.

69 BVerfG, Beschl. v. 13.05.1980, Az. 1 BvR 103/77, BVerfGE 54, 129, 137 - Kunstkritik; st. Rspr.; siehe z.B. BGH, Urt. v. 11.03.2008, Az. VI ZR 7/07, NJW 2008, 2110 Rn. 15 - „Gen-Milch“; BGH, Urt. v. 12.04.2016, Az. VI ZR 505/14, MDR 2016, 648 Rn. 11 - Organentnahme; BGH, Urt. v. 14.05.2013, Az. VI ZR 269/12, BGHZ 197, 213 Rn. 14 - Google.

70 BGH, Urt. v. 08.07.1980, Az. VI ZR 159/78, BGHZ 78, 9, 15 - „Medizin-Syndikat“ III; BGH, Urt. v. 17.12.1991, Az. VI ZR 169/91, NJW 1992, 1314, 1315 - Kassenärztliche Vereinigungen.

71 BVerfG, Beschl. v. 09.10.1991, Az. 1 BvR 221/90, BVerfGE 85, 23, 33 f. - Arbeitskreis Umwelt und Frieden; BGH, Urt. v. 16.06.1998, Az. VI ZR 205/97, BGHZ 139, 95, 104 - Stolpe; BGH, Urt. v. 09.12.2003, Az. VI ZR 38/03, NJW 2004, 1034, 1035 - Caroline von Hannover und Udo Jürgens Rn. 17; BGH, Urt. v. 25.11.2003, Az. VI ZR 226/02, NJW 2004, 598, 599 - „Klinik Monopoly“.

72 BVerfG, Beschl. v. 25.10.2005, Az. 1 BvR 1696/98, BVerfGE 114, 339, 350 - Stolpe; BVerfG, Beschl. v. 19.12.2007, Az. 1 BvR 967/05, NJW 2008, 1654 Rn. 35 - Schiffskoffer.

73 BVerfG, Beschl. v. 25.10.2005, Az. 1 BvR 1696/98, BVerfGE 114, 339, 350 - Stolpe; BVerfG, Beschl. v. 19.12.2007, Az. 1 BvR 967/05, NJW 2008, 1654 Rn. 35 - Schiffskoffer; vgl. BGH, Urt. v. 11.03.2008, Az. VI ZR 7/07, NJW 2008, 2110 Rn. 27 - „Gen-Milch“.

74 BGH, Urt. v. 10.12.1991, Az. VI ZR 53/91, NJW 1992, 1312, 1313 - Bezirksleiter Straßenbauamt. 
Eine zentrale Herausforderung für die Rechtsprechung wird die Frage sein, wie Äußerungen einer Kommunikations-KI auszulegen sind. Eine erste Präzedenz hierzu hat der BGH mit seiner Entscheidung zu Googles Suchergänzungs-Funktion geschaffen. Der BGH entschied, dass auf diese Weise generierten Suchbegriffen nicht nur der Inhalt zu entnehmen sei, dass Nutzer diese Begriffe zur Recherche eingegeben haben oder dass Webseiten diese Begriffe enthalten, sondern dass zwischen der Eingabe des Namens einer Person und dem vorgeschlagenen Ergänzungsbegriff auch ein sachlicher Zusammenhang bestehe. ${ }^{75}$ Der BGH begründete dies damit, dass in der Praxis häufig die Erwartung bestätigt würde, dass die vorgeschlagenen Wortkombinationen inhaltliche Bezüge $\mathrm{zu}$ dem Suchbegriff widerspiegelten. ${ }^{76}$ Daher verpflichtete der BGH Google dazu, solche aus Sicht des BGH ehrverletzenden Ergänzungsvorschläge zu unterlassen.

Diese Rechtsprechung begegnet jedoch grundsätzlichen Bedenken im Hinblick auf die rechtliche Bewältigung der Internetkommunikation mittels KI. Suchmaschinen beruhen nicht auf einer redaktionellen, sondern algorithmischen Strukturierung von Informationen. Mit seiner Entscheidung adelt der BGH eine algorithmisch-quantitative Wahrscheinlichkeitsrechnung - der Ergänzungsbegriff könnte inhaltlich relevant sein - zu einer anthropogen-qualitativen Schlussfolgerung: Aus Sicht der Nutzer sei der Ergänzungsbegriff inhaltlich relevant. Vereinfacht formuliert: Wenn auf die Eingabe des Namens eines Unternehmens der Begriffsvorschlag „Scientology“ erscheint, dann zögen die Nutzer daraus nicht die zutreffende Schlussfolgerung, dass ein Algorithmus diesen Ergänzungsvorschlag mittels einer Wahrscheinlichkeitsrechnung auf der Grundlage früherer Nutzereingaben sowie betreffender Webseiten generiert hat. Stattdessen folgerten die Nutzer unzutreffend, dass der Ergänzungsvorschlag suggeriere, das Unternehmen habe Verbindungen zu Scientology. Damit offenbart der BGH nicht nur eine äußerst pessimistische Einschätzung der Fähigkeit von Suchmaschinennutzern, algorithmisch generierte Informationen richtig einzuordnen. Was noch schwerer wiegt ist die Tatsache, dass der BGH diesem Fehlen an sog. internet literacy seinen höchstrichterlichen Segen erteilt: Ein unbefangener, objektiver und unvoreingenommener Durchschnitts-Suchmaschinennutzer darf demnach unzutreffend schlussfolgern, dass der Ergänzungsbegriff inhaltlich-qualitativ und nicht nur algorithmischquantitativ relevant sei.

Nach der Rechtsprechung des BGH ist es daher grundsätzlich möglich, dass eine Kommunikations-KI Persönlichkeitsrechte ebenso beeinträchtigen kann wie menschliche

75 BGH, Urt. v. 14.05.2013, Az. VI ZR 269/12, BGHZ 197, 213 Rn. 13 - Google.

76 BGH, Urt. v. 14.05.2013, Az. VI ZR 269/12, BGHZ 197, 213 Rn. 16 - Google. 
Kommunikation. Sofern sich die Äußerungen einer Kommunikations-KI einem Diensteanbieter zurechnen lassen (dazu nachfolgend b) und c)), handelt es sich hierbei um seine „eigene[n] Informationen“ i.S.d. $§ 7$ Abs. 1 TMG, für die er „,nach den allgemeinen Gesetzen verantwortlich“ ist.

\section{b) Adäquat kausale Verletzungshandlung}

Liegt eine Rechtsgutsbeeinträchtigung durch Kommunikations-KI vor, so stellt sich des Weiteren die Frage, worin genau die Verletzungshandlung besteht. Auf den ersten Blick scheint die Verletzungshandlung in der Kommunikation der ehrverletzenden oder privaten Information oder in der Veröffentlichung eines Bildes durch die KI selbst zu bestehen. Dies setzt aber voraus, dass die KI zu einer Verletzungshandlung überhaupt fähig ist. Das wiederum verlangt, dass eine KI im deliktsrechtlichen Sinne handeln kann. Eine Handlung im deliktsrechtlichen Sinne kann indessen nur in einem willensgesteuerten menschlichen Verhalten bestehen. ${ }^{77} \mathrm{Ob}$ man einer Maschine einen „Willen“ unterstellen kann, ist Auslegungssache ${ }^{78}$; in jedem Fall ist es kein menschliches Verhalten und damit de lege lata ${ }^{79}$ nicht von $\S 823$ Abs. 1 BGB umfasst. Auch fehlt es einer KI am Verschulden i.S.d. $\S \S 823$ Abs. 1, 276 Abs. 1 BGB. Abzustellen ist daher auf den Anbieter des KI-Dienstes. Zu prüfen ist daher in jedem Einzelfall, ob eine Rechtsverletzung, die vermeintlich durch eine KI „begangen“ wurde, dem Diensteanbieter zugerechnet werden kann.

Der Betrieb einer Kommunikations-KI ist für eine durch diese KI „begangene“ Rechtsgutsbeeinträchtigung naturwissenschaftlich kausal. ${ }^{80}$ Fraglich ist aber, ob der Betrieb der KI den Erfolg auch ,in adäquater Weise“ verursacht hat. Dies ist der Fall, wenn der Betrieb „die objektive Möglichkeit eines Erfolges von der Art des eingetretenen generell in nicht unerheblicher Weise erhöht hat. “" ${ }^{\text {81 }}$ Ausgeschlossen werden sollen solche Fälle, in denen „nur unter ganz besonders eigenartigen, ganz unwahrscheinlichen und nach dem regelmäßigen Lauf der Dinge außer Betracht zu lassenden Umständen“ die Begebenheit zur Herbeiführung des eingetretenen Erfolges geeignet gewesen ist. ${ }^{82}$

\footnotetext{
77 Deutsch/Ahrens, Deliktsrecht, 6. Aufl. 2016, Rn. 3, 34, 36.

78 Dies hängt wiederum davon ab, ob man „Willen“ als anthropologisches Konzept versteht (s.o.).

79 Zur möglichen Rechtsentwicklung de lege ferenda unter V.1.

80 Vgl. Volkmann, MMR 2018, 58, 61; Denga, CR 2018, 69, 72.

81 BGH, Urt. v. 23.10.1951, Az. I ZR 31/51, BGHZ 3, 261, 266 - Schleusenfall.

82 RG, Urt. v. 4.7.1938, Az. V 17/38, RGZ 158, 34, 38 - Silberfüchse-Fall.
} 
KI setzt nach der hier verwendeten Arbeitsdefinition bereits begrifflich voraus, dass das System autonom handelt und sein Verhalten daher gerade nicht vorhersehbar ist (siehe unter II. 3.). Entscheidend für die Adäquanz der Verletzungshandlung ist aber nicht, ob der konkret eingetretene Erfolg vorhersehbar war oder außerhalb aller Lebenswahrscheinlichkeit liegt, sondern ob die Möglichkeit dieses Erfolges vorhersehbar erhöht worden ist. Dies belegt wiederum, dass es notwendig ist, zwischen einzelnen Formen schwacher KI zu differenzieren. Dass etwa Kommunikations-KI dazu neigt, Persönlichkeitsrechte zu verletzen, ist sicherlich nicht außerhalb aller Lebenswahrscheinlichkeit, denn wo kommuniziert wird, wird die Möglichkeit einer Persönlichkeitsrechtsverletzung vorhersehbar erhöht. ${ }^{83}$ Dass „Manifestationen Künstlicher Intelligenz“, wie sie das Europäischen Parlament identifiziert $\mathrm{zu}$ haben glaubt, aufgrund autonomer Entscheidungen eine neue industrielle Revolution entfesseln (und im Anschluss daran möglicherweise doch noch die Weltherrschaft an sich reißen) ist demgegenüber nach dem gegenwärtigen Stand der Informatik außerhalb aller Lebenswahrscheinlichkeit. ${ }^{84}$

\section{c) Schutzzweck der Norm}

Für Kommunikations-KI ist nicht die empirische Adäquanztheorie, sondern die wertende Lehre vom Schutzzweck der Norm das geeignete Instrument, um eine überzogene Zurechnung der „Handlungen“ von Kommunikations-KI an ihren Anbieter auszuschließen. Inwieweit dem Anbieter einer KI von dieser „begangene“ Rechtsverletzungen zugerechnet werden können, bestimmt sich zunächst danach, ob dem Anbieter ein Handeln oder ein Unterlassen vorgeworfen wird. Der Unterschied ist deswegen erheblich, weil Unterlassen im Unterschied zum aktiven Tun nur dann haftungsbegründend ist, wenn der Betroffene durch eine Verkehrssicherungspflicht zum Handeln verpflichtet gewesen war.

Es wird vorgeschlagen, folgende Fallgruppen zu unterscheiden: (1.) Die Rechtsgutsverletzung ist bereits unmittelbar im Algorithmus selbst angelegt (sog. algorithm bias), oder (2.) die Rechtsgutsverletzung ist nicht unmittelbar im Algorithmus angelegt, sondern die KI hat die die Rechtsgutsverletzung begründende konkrete Aussage autonom und damit unvorhersehbar ${ }^{85}$ getroffen, insbesondere weil sie die erforderliche Information ,gelernt“ hat.

\footnotetext{
83 Vgl. zur objektiven Zurechnung im Strafrecht mit gleichem Ergebnis Gleß/Weigend, ZStW 126 (2014), 561, 581 f.; Seher, in: Gless/Seelmann (Hrsg.), Intelligente Agenten und das Recht, 2016, 45, 53.

84 Statt vieler Tegmark, Life 3.0, 2017, S. 40 ff.

85 Maßgeblich ist hier, dass die konkrete Aussage für den Betreiber unvorhersehbar war. Ob eine Persönlichkeitsrechtsverletzung durch die KI generell vorhersehbar war, ist eine Frage der Adäquanz; wie dargestellt (siehe unter b)), dürfte dies regelmäßig zu bejahen sein.
} 


\section{aa) Algorithm bias}

Ein sog. algorithm bias ist dann gegeben, wenn die KI bereits das strategische Ziel verfolgt (siehe dazu die Arbeitsdefinition unter II. 2.), Persönlichkeitsrechtsverletzungen zu begehen. Ein Beispiel hierfür ist, dass ein Chatbot oder ein Social Bot die Meinungsbildung durch Diffamierung politischer Gegner beeinflussen soll. ${ }^{86}$ In diesem Fall bedarf es für eine Haftung nach $\S 823$ Abs. 1 BGB keiner zusätzlichen Verletzung einer Verkehrssicherungspflicht, und gegebenenfalls kommt sogar $\S 826$ BGB in Betracht. Auch dürfte in diesem Fall Vorsatz im strafrechtlichen Sinne vorliegen, sodass $\S 823$ Abs. 2 BGB i.V.m der strafrechtlichen Schutznorm, etwa $\S 187$ StGB, einschlägig ist. ${ }^{87}$

$\mathrm{Ob}$ indessen ein algorithm bias vorliegt, ist Tatfrage. Es ist im Einzelfall schwierig nachzuweisen, ob eine Rechtsgutsverletzung auf einer Programmierung der Software, dem fehlerhaften Gebrauch der KI, dem Eingreifen des Verwenders oder eines Dritten oder der Autonomie der KI beruht. ${ }^{88}$ Vom Kläger (und vom Gericht) wird insofern nicht zu erwarten sein, den Algorithmus im Einzelnen nachzuvollziehen und den Programmierbefehl zu finden, in dem die Rechtsgutsverletzung möglicherweise angelegt ist. Der exakte Algorithmus eines Suchmaschinenbetreibers ist regelmäßig ein gut gehütetes Geheimnis. Dies spricht dafür, entweder in der Rechtsprechung oder durch Gesetzesänderung eine Beweislastumkehr zugunsten des Geschädigten vorzunehmen (dazu ausführlich unter V. 3.).

\section{bb) Autonome Entscheidung der KI}

Lässt sich - gegebenenfalls trotz einer Beweislastumkehr - nicht belegen, dass die Rechtsgutsverletzung unmittelbar im Algorithmus angelegt war, dann ist anzunehmen, dass die KI die Verletzungs-,„Handlung“ autonom vorgenommen hat, insbesondere weil sie die erforderliche Information selbständig ,gelernt“ hat. Dies war etwa der Fall bei Googles Suchergänzungsfunktion: Dass die Suchergänzungsfunktion den Namen des klägerischen Unternehmens mit „Scientology“ ergänzte, war von Googles Programmierern nicht konkret vorhersehbar; die KI hat diese Information vielmehr durch frühere Eingaben der Nutzer „gelernt“. Gleiches gilt für Microsofts Tay. Microsoft hatte Tay sicher nicht darauf ausgelegt,

\footnotetext{
86 Sog. „bösartige (malicious) Bots“ (Volkmann, MMR 2018, 58, 59 m.w.N.).

87 Vgl. Gleß/Weigend, ZStW 126 (2014), 561, 580.

88 Beck, JR 2009, 225, 227. Zum Stand der wissenschaftlichen Forschung zu Werten und Vorurteilen in Computerprogrammen etwa Friedman/Nissenbaum, ACM Transactions on Information Systems 14 (1996), 330; Hildebrandt/Koops/Jaquet-Chiffelle, Minnesota Journal of Law, Science \& Technology 11 (2010), 497; Diakopoulos, Digital Journalism 3 (2015), 398; van der Sloot/van Schendel, International and comparative legal study on Big Data (WRR Working Paper, 2016), S. 139.
} 
rassistische und sexistische Phrasen $\mathrm{zu}$ verbreiten; Tay hat dies vielmehr erst von seinen Gesprächspartnern aufgenommen.

In diesen Fällen liegt der „Schwerpunkt der Vorwerfbarkeit“ nicht darin, dass die Rechtsgutsverletzung bereits im Algorithmus angelegt war, sondern darin, dass das betreffende Unternehmen es unterließ, die von der KI „begangenen“ Rechtsgutsverletzungen zu unterbinden. ${ }^{89}$ Alternativ ließe sich in dem Betrieb der KI zwar eine aktive Handlung erblicken. Diese stellt jedoch eine nur mittelbare Rechtsgutsverletzung dar, die erst durch das - zumeist durch die Eingaben Dritter beeinflusste - „Lernen“ der KI zu einer unmittelbaren Rechtsgutsverletzung wurde. Im Ergebnis macht dies keinen Unterschied: In beiden Fällen Unterlassen und mittelbare Rechtsgutsverletzung - muss der Anbieter der KI eine Verkehrssicherungspflicht verletzt haben, damit ihm die Rechtsgutsverletzung zugerechnet werden kann. Fraglich ist daher, ob und inwieweit den Anbieter einer Kommunikations-KI eine solche Verkehrssicherungspflicht trifft.

Inhalt der Verkehrssicherungspflicht ist es, dass derjenige der eine Gefahrenquelle schafft, „alle nach Lage der Verhältnisse erforderlichen Sicherungsmaßnahmen zum Schutze anderer

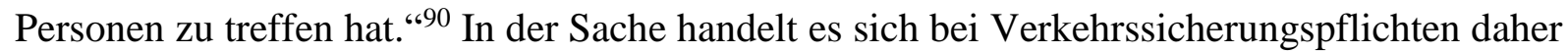
um deliktische Sorgfaltspflichten. ${ }^{91}$ So verhält es sich bei einer Kommunikations-KI: Wer eine solche KI betreibt, schafft die Gefahr, dass diese KI Rechte anderer verletzt, und hat zwar nicht absolute, aber mögliche und zumutbare Sorge dafür zu tragen, dass dies nicht geschieht. ${ }^{92}$ Mit dem BGH ist anzunehmen, dass es sich bei den Verkehrssicherungspflichten des Anbieters einer Kommunikations-KI um Prüfungspflichten handelt. ${ }^{93}$ Der BGH hierzu: „Voraussetzung einer Haftung des Betreibers einer Suchmaschine mit entsprechender Hilfsfunktion ist [...] eine Verletzung von Prüfungspflichten. Deren Bestehen wie deren Umfang richtet sich im Einzelfall nach einer Abwägung aller betroffenen Interessen und relevanten rechtlichen Wertungen. Überspannte Anforderungen dürfen im Hinblick darauf, dass es sich um eine erlaubte Teilnahme am geschäftlichen Verkehr handelt, nicht gestellt werden. Entsprechend den zur Störerhaftung entwickelten Grundsätzen kommt es entscheidend darauf an, ob und inwieweit dem in Anspruch Genommenen nach den

89 Siehe BGH, Urt. v. 14.05.2013, Az. VI ZR 269/12, BGHZ 197, 213 Rn. 25 - Google; krit. Gounalakis, NJW 2013, 2321, 2323.

90 BGH, Urt. v. 22.10.1974, Az. VI ZR 149/73, NJW 1975, 108 - Stahlbaumatte.

91 Looschelders, Schuldrecht BT, 13. Aufl. 2018, Rn. 1176; Wagner, in: Münchener Kommentar, Band 7, 7. Aufl. 2017, § 823 Rn. 311 ff.; Kötz/Wagner, Deliktsrecht, 13. Aufl. 2016, Rn. 127, 170.

92 Siehe Kötz/Wagner, Deliktsrecht, 13. Aufl. 2016, Rn. 183.

93 BGH, Urt. v. 14.05.2013, Az. VI ZR 269/12, BGHZ 197, 213 Rn. 29 - Google; Gounalakis, NJW 2013, 2321, 2323. 
Umständen eine Prüfung zuzumuten ist“. ${ }^{94}$ Erforderlich für Inhalt und Umfang der Prüfungspflichten ist somit zweierlei: Zum einen eine Abwägung der betroffenen Interessen. Dieses Abwägungsgebot ist auch von anderer Seite indiziert: Bei sog. Rahmenrechten wie dem allgemeinen Persönlichkeitsrecht muss die Rechtswidrigkeit positiv festgestellt werden. Dies erfordert eine umfassende Abwägung unter Berücksichtigung der konfligierenden Grundrechtspositionen (dazu d)). Zum andern ist zu ermitteln, welche „relevanten rechtlichen Wertungen“ Bestehen und Umfang der Prüfungspflichten beeinflussen (dazu e)).

\section{d) Abwägung der betroffenen Interessen}

Für die Abwägung ist zunächst festzustellen, welche Interessen im Einzelfall miteinander konfligieren. Auf Seiten des Verletzten ist das betroffene Persönlichkeitsrecht zumeist grundrechtlich geschützt, ist doch das allgemeine Persönlichkeitsrecht aus Art. 2 Abs. 1 i.V.m. Art. 1 Abs. 1 GG mit dem zivilrechtlichen allgemeinen Persönlichkeitsrecht weitgehend deckungsgleich. ${ }^{95}$ Aus dem europäischen und internationalen Recht kommen zudem die von Art. 17 Abs. 1 IPbpR, Art. 8 Abs. 1 EMRK und Art. 7 EUGRCh geschützten Persönlichkeitsrechte, insbesondere Ehre, Reputation und Privatheit ${ }^{96}$, in Betracht.

Problematisch ist demgegenüber, auf welches rechtlich geschützte Interesse sich der Anbieter einer KI berufen kann. Geklärt ist zunächst, dass sich eine KI de lege lata nicht auf Grundrechte berufen kann, da es sich bei KI weder um einen Menschen noch um eine juristische Person i.S.d. Art. 19 Abs. 3 GG oder um eine Personenvereinigung handelt. ${ }^{97}$ Demgegenüber kann sich der Anbieter einer KI auf Grundrechte berufen. Dies sind insbesondere die Berufsfreiheit (Art. 15 EUGRCh, Art. 12 GG), die unternehmerische Freiheit nach Art. 16 EUGRCh, die Kommunikationsgrundrechte der Art. 19 Abs. 2 IPbpR, Art. 11 Abs. 1 EUGRCh, Art. 10 EMRK und Art. 5 Abs. 1 Satz 1 GG sowie gegebenenfalls etwa bei algorithmischem Journalismus - auch die Medienfreiheiten der Art. 11 Abs. 2 EUGRCh bzw. Art. 5 Abs. 1 Satz 2 GG. Allerdings erweist sich KI bei näherem Hinsehen auch hier als juristische Herausforderung. Ausweislich seines Wortlauts schützt Art. 5 Abs. 1

94 BGH, Urt. v. 14.05.2013, Az. VI ZR 269/12, BGHZ 197, 213 Rn. 29 - Google.

95 Es bestehen aber auch Unterschiede, etwa hinsichtlich des postmortalen Persönlichkeitsschutzes; siehe z.B. BVerfG, Beschl. v. 22.08.2006, Az. 1 BvR 1168/04, NJW 2006, 3409, 3410 - Blauer Engel.

96 Statt vieler EGMR, Chauvy u.a./Frankreich [2004] Beschwerde-Nr. 64915/01 [70], Radio France u.a./Frankreich [2004] Beschwerde-Nr.53984/00 [31] und Pfeifer/Österreich [2007] Beschwerde-Nr. [35] (zur Reputation); Polanco Torres et Movilla Polanco/Spanien [2010] Beschwerde-Nr. 34147/06 [40] und A./Norwegen [2009] Beschwerde-Nr. 28070/06 [64] (zur Ehre); Botta/Italien [1998] BeschwerdeNr.153/1996/772/973 [32] und Von Hannover/Deutschland (Nr. 1) [2004] Beschwerde-Nr.59320/00 [50] (zur Privatheit).

97 Zu möglichen Entwicklungen de lege ferenda wiederum unter V. 1. 
Satz 1 GG lediglich das Recht, seine Meinung zu verbreiten. ${ }^{98}$ Berechtigter des Grundrechts der Meinungsfreiheit ist daher anscheinend nur der Meinungsträger selbst. Die Äußerung einer KI hingegen, die in dieser Form nicht unmittelbar im Algorithmus vorgesehen ist, sondern die die KI erst ,gelernt“ und dann autonom generiert hat, stellt hingegen oftmals nicht die eigene Meinung (oder Tatsachenbehauptung) des Anbieters oder Herstellers der KI dar. So dürfte es nicht der Auffassung der Alphabet-Holding entsprechen, den Kläger der Google-Entscheidung in einen sachlichen Zusammenhang mit Scientology zu bringen, und Microsofts Firmen-Policy steht Tays Hassreden und Sexismus ausdrücklich entgegen. ${ }^{99}$ BVerfG und BGH weisen jedoch regelmäßig darauf hin, dass Art. 5 Abs. 1 Satz 1 GG nicht nur die individuelle Meinung, sondern auch den Kommunikationsprozess als solchen, den „Markt der Meinungen“, schützt. ${ }^{100} \mathrm{Zu}$ diesem Kommunikationsprozess könne ,auch die Mitteilung einer fremden Meinung oder Tatsachenbehauptung zählen, und zwar auch dann, wenn der Mitteilende sich diese weder zu eigen macht noch sie in eine eigene Stellungnahme einbindet, sondern lediglich verbreitet". ${ }^{101}$ Es ist allerdings problematisch, ob diese Rechtsprechung auf KI-generierte Informationen übertragen werden kann. Dafür müsste es sich bei der Äußerung der KI um eine vom Anbieter oder Hersteller „fremde“ Meinung oder Tatsachenbehauptung handeln. Eine Meinung oder Tatsachenbehauptung ist jedoch dann nur eine „fremde“, wenn es die einer anderen Person ist. Auch dies trifft bei näherem Hinsehen nicht zu: Die von einer KI verbreitete Meinung oder Tatsachenbehauptung ist nicht die einer anderen Person, sondern von der KI selbst generiert. Befremdlich erschiene es, die Meinung oder Tatsachenbehauptung deswegen als „fremd“ zu bezeichnen, weil es „die der KI“ ist. Eine KI hat keine eigene Meinung und stellt auch keine eigenen Tatsachenbehauptungen auf, sondern generiert beides algorithmisch auf der Grundlage vorhandener Eingaben und Datenbanken. So ist es in dem BGH-Urteil nicht die Behauptung von Googles

98 Dieses Problem stellt sich bei Art. 19 Abs. 2 IPbpR, Art. 10 Abs. 1 EMRK und Art. 11 Abs. 1 EUGRCh nicht, da diese Kommunikationsgrundrechte bereits ihrem Wortlaut nach auch das Recht umfassen, Tatsachenbehauptungen und Meinungen lediglich $\mathrm{zu}$ verbreiten und nicht nur selbst zu behaupten (Oster, European and International Media Law, 2017, S. 65 f.).

99 Siehe https://www.microsoft.com/en-us/concern/hatespeech.

100 BVerfG, Beschl. 25.06.2009, Az. 1 BvR 134/03, AfP 2009, 480 Rn. 66 - Effecten-Spiegel; vgl. BGH, Urt. v. 17.11.2009, Az. VI ZR 226/08, NJW 2010, 760 Rn. 13 - Helmut Markwort; BGH, Urt. v. 27.03.2012, Az. VI ZR 144/11, NJW 2012, 2345 Rn. 18 - RSS-Feed; BGH, Urt. v. 23.09.2014, Az. VI ZR 358/13, NJW 2015, 489 Rn. 28 - Ärztebewertung II; BGH, Urt. v. 04.04.2017, Az. VI ZR 123/16, NJW 2017, 2029 Rn. 24 - Klinikbewertung.

101 BVerfG, Beschl. 25.06.2009, Az. 1 BvR 134/03, AfP 2009, 480 Rn. 58 - Effecten-Spiegel; vgl. BGH, Urt. v. 17.11.2009, Az. VI ZR 226/08, NJW 2010, 760 Rn. 13 - Helmut Markwort; BGH, Urt. v. 27.03.2012, Az. VI ZR 144/11, NJW 2012, 2345 Rn. 18 - RSS-Feed; BGH, Urt. v. 04.04.2017, Az. VI ZR 123/16, NJW 2017, 2029 Rn. 24 - Klinikbewertung. 
Suchergänzungsfunktion, dass eine sachliche Verbindung zwischen dem klagenden Unternehmen und Scientology bestehe, sondern ein Vorschlag, der auf der Grundlage einer Wahrscheinlichkeitsrechnung generiert wurde. Ebenso abwegig ist es, von dem Chatbot Tay zu behaupten, dieser habe selbst die Meinung vertreten, Juden seien für die Anschläge des 11. September 2001 verantwortlich oder Feminismus sei eine Krankheit. ${ }^{102}$

Eine von einer KI generierte Tatsachenbehauptung oder Meinungsäußerung ist daher bei Lichte besehen keine „fremde“ Behauptung oder Meinung. Fraglich ist daher, ob sich der Anbieter einer Kommunikations-KI auch hinsichtlich autonom generierter Meinungsäußerungen und Tatsachenbehauptungen auf Art. 5 Abs. 1 Satz 1 GG berufen kann, die er sich nicht zu eigen macht oder von denen er sich sogar ausdrücklich distanziert. Dies ist im Ergebnis zu bejahen. Die Meinungsfreiheit ist nicht allein als intrinsisches Recht zu verstehen, welches dem Schutz des sich Äußernden selbst dient. Die Meinungsfreiheit ist auch ein konsequentialistisches Recht, welches den Kommunikationsprozess als solchen schützt. ${ }^{103}$ Indem KI einen Beitrag zu diesem Kommunikationsprozess generiert, nimmt die KI an dem geschützten Kommunikationsprozess teil. Ebenso wie dem Anbieter oder Hersteller die Äußerungen der KI in deliktsrechtlicher Hinsicht zugerechnet werden (dazu unter IV. 2.), muss ihnen konsequenterweise die Teilnahme ihrer KI am Kommunikationsprozess zugerechnet werden.

Im Hinblick auf algorithmischen Journalismus wird noch zu klären sein, inwieweit sich Nutzer solcher KI auf die Medienprivilegien berufen können. ${ }^{104}$ Dies wird insbesondere davon abhängen, ob die KI imstande ist, pressemäßige Sorgfalt wahrzunehmen und die Rechte anderer respektiert. ${ }^{105}$

\section{e) Relevante rechtliche Wertungen}

Auch wenn sich Anbieter und Hersteller einer KI die von ihrer KI generierte Tatsachenbehauptung oder Meinungsäußerung explizit nicht zu eigen machen oder sich sogar davon distanzieren, können sie sich somit in der Abwägung mit konfligierenden

\footnotetext{
102 Siehe die Nachweise zu Tays Äußerungen bei https://www.theguardian.com/world/2016/mar/29/microsofttay-tweets-antisemitic-racism.

103 Oster, Media Freedom as a Fundamental Right, 2015, S. 13 ff.

104 Dazu Weberling, NJW 2018, 735, 737.

105 Art. 10 Abs. 2 EMRK, Art. 5 Abs. 2 GG; vgl. EGMR, Fressoz und Roire/Frankreich [1999] BeschwerdeNr. 29183/95 [54]; Pedersen und Baadsgaard/Dänemark [2004] Beschwerde-Nr. 49017/99 [78]; Stoll/Schweiz [2007] Beschwerde-Nr. 69698/01 [103]; Axel Springer AG/Deutschland (Nr. 1) [2012] Beschwerde-Nr. 39954/08 [93]; BVerfG, Beschl. v. 25.01.1961, Az. 1 BvR 9/57, BVerfGE 12, $113,130-$ Schmid/Spiegel; BGH, Urt. v. 30.01.1979, Az. VI ZR 163/77, NJW 1979, 1041 - Exdirektor; BGH, Urt. v. 22.11.2005, Az. VI ZR 204/04, NJW 2006, 601 Rn. 18 - Erzbistum.
} 
Persönlichkeitsrechten nicht nur auf die Wirtschaftsgrundrechte (etwa Art. 12 GG, Art. 16 EUChFR) sondern auch auf die Kommunikationsgrundrechte berufen. ${ }^{106}$ Dies wirkt sich unmittelbar auf ihre Prüfungspflichten aus. Zu erinnern ist daran, dass sich nach dem BGH das Bestehen und der Umfang der Prüfungspflichten des Anbieters einer Kommunikations-KI - im Fall des BGH einer Suchmaschinen-Ergänzungsfunktion - „im Einzelfall nach einer Abwägung aller betroffenen Interessen und relevanten rechtlichen Wertungen“ bestimmt. ${ }^{107}$ Die „betroffenen Interessen“ sind nunmehr ermittelt: Für den Geschädigten streiten die Persönlichkeitsrechte, der Anbieter einer KI kann sich auf Wirtschafts- und Kommunikationsgrundrechte berufen. $\mathrm{Zu}$ fragen ist nunmehr danach, welche ,relevanten rechtlichen Wertungen“ bestehen. Welche Prüfungspflichten dem Anbieter einer Suchmaschine für eine von der Suchmaschine generierte Ergänzungsfunktion zuzumuten sind, entnimmt der BGH den Wertungen der Art. 14 und 15 e-commerce-Richtlinie bzw. $\S 7$ Abs. 2 Satz 1, 10 TMG. Zwar unterfallen durch KI generierte Inhalte nicht dem Anwendungsbereich des 4. Abschnitts des II. Kapitels der e-commerce-Richtlinie. Gleichwohl unterwarf der BGH den Suchmaschinenbetreiber Google (nur) einer besonderen Prüfungspflicht, „ebenso wie bei der Haftung eines Hostproviders wegen der Verbreitung einer in einem Blog enthaltenen Äußerung eines Dritten“. ${ }^{108}$ Der BGH entschied jedoch gegen eine allgemeine Prüfungspflicht, obwohl dies mangels Anwendbarkeit des Art. 15 Abs. 1 ecommerce-Richtlinie bzw. § 7 Abs. 2 Satz 1 TMG zulässig gewesen wäre. Der Anbieter einer Suchmaschine sei grundsätzlich nicht dazu verpflichtet, die algorithmisch generierten Suchergänzungsvorschläge generell vorab auf etwaige Rechtsverletzungen zu kontrollieren. Dies würde den Betrieb einer Suchmaschine mit einer der schnellen Recherche der Nutzer dienenden Suchergänzungsfunktion zumindest unzumutbar erschweren. Den Anbieter einer Internet-Suchmaschine trifft deshalb grundsätzlich erst dann eine Prüfungspflicht, wenn er Kenntnis von der Rechtsverletzung erlangt, etwa wenn ein Betroffener auf eine Verletzung seiner Persönlichkeitsrechte hinweist. ${ }^{109}$

Die Rechtsprechung des BGH, die Art. 14 und 15 e-commerce-Richtlinie bzw. $\S 7$ Abs. 2 Satz 1, 10 TMG zwar nicht ausdrücklich, aber in der Sache auf die Ergänzungsfunktion von

\footnotetext{
106 So auch ohne nähere Begründung BGH, Urt. v. 14.05.2013, Az. VI ZR 269/12, BGHZ 197, 213 Rn. 22 Google; den Grundrechtsschutz ebenfalls bejahend Milker, ZUM 2017, 216, 217 f.; zur Dogmatik des - mit europäischen Kommunikationsgrundrechten nur begrenzt vergleichbaren - Ersten Zusatzartikels zur USVerfassung Benjamin, University of Pennsylvania Law Review 161 (2013), 1445.

107 BGH, Urt. v. 14.05.2013, Az. VI ZR 269/12, BGHZ 197, 213 Rn. 29 - Google.

108 BGH, Urt. v. 14.05.2013, Az. VI ZR 269/12, BGHZ 197, 213 Rn. 29 - Google.

109 BGH, Urt. v. 14.05.2013, Az. VI ZR 269/12, BGHZ 197, 213 Rn. 30 - Google.
} 
Suchmaschinenbetreibern analog anwendet, ist zu begrüßen. Die rechtlichen Wertungen dieser Vorschriften lassen sich auf die Abwägung der betroffenen Interessen zwischen Anbietern einer Kommunikations-KI und Geschädigten übertragen und schaffen einen angemessenen Ausgleich. Grundsätzlich verpflichtet Art. 18 e-commerce-Richtlinie einen Diensteanbieter nicht nur dazu, ein Kommunikationsdelikt zu beenden, sondern auch dazu, Vorsorge gegen erneute Rechtsverletzungen $\mathrm{zu}$ treffen. ${ }^{110}$ Die Grenze für diese Sorgfaltspflicht legt Art. 15 Abs. 1 e-commerce-Richtlinie fest. Von einem Diensteanbieter darf nicht verlangt werden, aktiv alle gespeicherten - analog gilt für Anbieter einer Kommunikations-KI: autonom generierten - Inhalte zu überwachen, um jeder künftigen Rechtsverletzung vorzubeugen. ${ }^{111}$ Den Diensteanbieter trifft daher keine Verpflichtung dazu, präventiv, auf eigene Kosten und zeitlich unbegrenzt ein unterschiedslos auf alle Kunden anwendbares System der Filterung einzurichten, mit dem sich eine Rechtsverletzung ermitteln lässt. ${ }^{112}$ In welchem Umfang einem Diensteanbieter aber spezifische Überwachungspflichten auferlegt werden dürfen, richtet sich danach, ob und inwieweit ihm nach den Umständen des Einzelfalls bei Abwägung aller betroffenen Interessen eine Prüfung zuzumuten ist. ${ }^{113}$ Hierzu gehören zunächst der Grad der Erkennbarkeit des Rechtsverstoßes, das Gewicht der angezeigten Rechtsverletzungen und die Erkenntnismöglichkeiten des Anbieters. ${ }^{114}$ Dabei ist zu berücksichtigen, dass sich eine behauptete Verletzung von Persönlichkeitsrechten häufig nur nach sorgfältiger rechtlicher und tatsächlicher Prüfung feststellen lässt. ${ }^{115}$ Ein Diensteanbieter muss nur dann handeln, wenn der Hinweis auf eine Rechtsverletzung so konkret gefasst ist, „dass der Rechtsverstoß auf der Grundlage der Behauptungen des Betroffenen unschwer - das heißt ohne eingehende rechtliche und tatsächliche Überprüfung -

${ }^{110}$ EuGH, Rs. C-324/09 [2011] L’Oréal SA u.a./eBay International AG u.a. [131-134]; BGH, Urt. v. 25.10.2011, Az. VI ZR 93/10, NJW 2012, 148 Rn. 24 - Blogspot; vgl. BGH, Urt. v. 11.03.2004, Az. I ZR 304/01, BGHZ 158, 236, 252 - Internet-Versteigerung I; BGH, Urt. v. 27.03.2012, Az. VI ZR 144/11, NJW 2012, 2345 Rn. 19 - RSS-Feed; BGH, Urt. v. 19.03.2015, Az.: I ZR 94/13, NJW 2015, 3443 Rn. 37 Hotelbewertungsportal; BGH, Urt. v. 01.03.2016, Az. VI ZR 34/15, NJW 2016, 2106 Rn. 23 Ärztebewertung III.

111 EuGH, Rs. C-324/09 [2011] L’Oréal SA u.a./eBay International AG u.a. [139].

112 EuGH, Rs. C-70/10 [2011] Scarlet Extended/SABAM u.a. und Rs. C-360/10 [2012] SABAM/Netlog.

113 BGH, Urt. v. 25.10.2011, Az. VI ZR 93/10, NJW 2012, 148 Rn. 26 - Blogspot; BGH, Urt. v. 14.05.2013, Az. VI ZR 269/12, BGHZ 197, 213 Rn. 29 - Google; BGH, Urt. v. 19.03.2015, Az.: I ZR 94/13, NJW 2015, 3443 Rn. 36 - Hotelbewertungsportal.

114 BGH, Urt. v. 25.10.2011, Az. VI ZR 93/10, NJW 2012, 148 Rn. 26 - Blogspot; BGH, Urt. v. 01.03.2016, Az. VI ZR 34/15, NJW 2016, 2106 Rn. 38 - Ärztebewertung III.

115 BGH, Urt. v. 19.04.2007, Az. I ZR 35/04, BGHZ 172, 119 Rn. 47 - Internet-Versteigerung II; BGH, Urt. v. 25.10.2011, Az. VI ZR 93/10, NJW 2012, 148 Rn. 25 - Blogspot; BGH, Urt. v. 19.03.2015, Az.: I ZR 94/13, NJW 2015, 3443 Rn. 36 - Hotelbewertungsportal. 
bejaht werden kann. “116 Für eine erhöhte Prüfungspflicht spricht es, wenn die Tätigkeit des Diensteanbieters eine gesteigerte Gefahr von Rechtsverletzungen birgt, wie dies etwa bei Microsofts Tay der Fall gewesen ist. ${ }^{117} \mathrm{Zu}$ beachten ist aber auch, ob die Tätigkeit des Diensteanbieters - hier des Betreibers der Kommunikations-KI - eine grundsätzlich erlaubte und regelmäßig sogar gesellschaftlich erwünschte Teilnahme am geschäftlichen Verkehr darstellt. $^{118}$

Ein (Unterlassungs-)Begehren gegenüber dem Anbieter einer Kommunikations-KI, etwa in Gestalt der Störerhaftung, darf daher nicht auf eine analog Art. 15 Abs. 1 e-commerceRichtlinie unzulässige Begründung einer allgemeinen Überwachungs- oder Nachforschungspflicht abzielen. ${ }^{119}$ Dies ist eine Ausprägung der Kommunikationsfreiheiten nach Art. 11 EUGRCh und Art. 10 EMRK, die nicht nur das Recht der Anbieter einer Kommunikations-KI einschließen, Informationen und Ideen zu verbreiten, sondern auch das Recht der Öffentlichkeit, solche von einer KI generierten Informationen zu empfangen. Eine allgemeine Prüfungspflicht würde den freien Informationsfluss hemmen. ${ }^{120}$ Art. 15 ecommerce-Richtlinie schließt jedoch die Auferlegung spezifischer Überwachungspflichten nicht aus, auf die wiederum auch klägerische Begehren gerichtet sein können. ${ }^{121}$ Die Richtlinie lässt nach Erwägungsgrund 48 ausdrücklich die Möglichkeit unberührt, dass die Mitgliedstaaten von Host-Providern verlangen, die nach vernünftigem Ermessen von ihnen zu erwartende und in innerstaatlichen Rechtsvorschriften niedergelegte Sorgfaltspflicht anzuwenden, um bestimmte Arten rechtswidriger Tätigkeiten aufzudecken und zu verhindern. Dies gilt analog für Anbieter von Kommunikations-KI.

Art. 14 e-commerce-Richtlinie, den $\S 10$ TMG in deutsches Recht umsetzt, gilt zwar seinem Wortlaut nach nur für eine dauerhafte Speicherung von Informationen. Sein Rechtsgedanke

\footnotetext{
116 BGH, Urt. v. 25.10.2011, Az. VI ZR 93/10, NJW 2012, 148 Rn. 26 - Blogspot.

117 Vgl. BGH, Urt. v. 23.09.2014, Az. VI ZR 358/13, NJW 2015, 489 Rn. 32 - Ärztebewertung II; BGH, Urt. v. 19.03.2015, Az.: I ZR 94/13, NJW 2015, 3443 Rn. 36 - Hotelbewertungsportal; BGH, Urt. v. 01.03.2016, Az. VI ZR 34/15, NJW 2016, 2106 Rn. 40 - Ärztebewertung III; so auch EGMR, Magyar Tartalomszolgáltatók Egyesülete und Index.hu Zrt/Ungarn [2016] Beschwerde-Nr. 22947/13 [49].

118 BGH, Urt. v. 14.05.2013, Az. VI ZR 269/12, BGHZ 197, 213 Rn. 29 - Google; BGH, Urt. v. 23.09.2014, Az. VI ZR 358/13, NJW 2015, 489 Rn. 39 f. - ̈̈rztebewertung II; BGH, Urt. v. 19.03.2015, Az.: I ZR 94/13, NJW 2015, 3443 Rn. 36 - Hotelbewertungsportal; BGH, Urt. v. 01.03.2016, Az. VI ZR 34/15, NJW 2016, 2106 Rn. 40 - Ärztebewertung III.

119 Vgl. BGH, Urt. v. 25.10.2011, Az. VI ZR 93/10, NJW 2012, 148 Rn. 24 - Blogspot; BGH, Urt. v. 27.03.2012, Az. VI ZR 144/11, NJW 2012, 2345 Rn. 19 - RSS-Feed; BGH, Urt. v. 19.03.2015, Az.: I ZR 94/13, NJW 2015, 3443 Rn. 31 - Hotelbewertungsportal; BGH, Urt. v. 01.03.2016, Az. VI ZR 34/15, NJW 2016, 2106 Rn. 19 - Ärztebewertung III.

120 Vgl. BGH, Urt. v. 27.03.2012, Az. VI ZR 144/11, NJW 2012, 2345 Rn. 19 - RSS-Feed.

121 Vgl. BGH, Urt. v. 18.11.2010, Az. I ZR 155/09, GRUR 2011, 617 Rn. 40 - Sedo; BGH, Urt. v. 19.03.2015, Az.: I ZR 94/13, NJW 2015, 3443 Rn. 31 - Hotelbewertungsportal.
} 
lässt sich aber ebenfalls auf Anbieter von Kommunikations-KI analog übertragen. Ein Anbieter einer Kommunikations-KI ist danach nicht für autonom generierte Informationen verantwortlich, wenn folgende Voraussetzungen erfüllt sind:

- Der Anbieter hat keine tatsächliche Kenntnis von der rechtswidrigen „Tätigkeit“ der KI (Art. 14 Abs. 1 Buchst. a) Var. 1 analog), und

- in Bezug auf Schadensersatzansprüche ist er sich auch keiner Tatsachen oder Umstände bewusst, aus denen die rechtswidrige „Tätigkeit“ der KI offensichtlich wird (Art. 14 Abs. 1 Buchst. b) Var. 2 analog), oder

- der Anbieter wird, sobald er diese Kenntnis oder dieses Bewusstsein erlangt, unverzüglich tätig, um die Kommunikation der Information zu verhindern (Art. 14 Abs. 1 Buchst. b) analog).

Art. 14 Abs. 1 Buchst. b) e-commerce-Richtlinie in analoger Anwendung verpflichtet den Anbieter somit dazu, „unverzüglich tätig“ zu werden, um die Kommunikation der rechtsverletzenden Information zu verhindern, sobald er Kenntnis oder Bewusstsein über Tatsachen oder Umstände erlangt hat, aus denen die rechtswidrige „Tätigkeit“ seiner KI offensichtlich wird. ${ }^{122}$ Daher hat der Betroffene die beanstandete Information zunächst beim Anbieter der KI zu melden. Antwortet dieser nicht „,innerhalb einer nach den Umständen angemessenen Frist“, so hat er die Kommunikation zu verhindern. ${ }^{123}$

Aus alledem folgt, dass eine Verhaltenspflicht des Anbieters (erst) nach Erlangung der Kenntnis von der Rechtsverletzung entstehen kann. ${ }^{124}$ Daher begründet die „Äußerung“ der KI, die Gegenstand der erstmaligen Mitteilung eines Rechtsverstoßes ist, noch keine eigene Verletzungshandlung. Hierfür ist eine vollendete Rechtsverletzung durch die KI nach Begründung der Pflicht zur Verhinderung weiterer Rechtsverletzungen erforderlich. ${ }^{125}$ Zudem muss eine gegen den Diensteanbieter ergangene Anordnung mit den betroffenen

${ }^{122}$ Zum Tatbestandsmerkmal der „Kenntnis“ EuGH, Rs. C-324/09 [2011] L’Oréal SA u.a./eBay International AG u.a. [120-122]; BGH, Urt. v. 25.10.2011, Az. VI ZR 93/10, NJW 2012, 148 Rn. 27 - Blogspot; BGH, Urt. v. 19.03.2015, Az.: I ZR 94/13, NJW 2015, 3443 Rn. 39 - Hotelbewertungsportal. Dazu Oster, Legal Studies 35 (2015), 348, 367.

123 Vgl. BGH, Urt. v. 25.10.2011, Az. VI ZR 93/10, NJW 2012, 148 Rn. 27 - Blogspot.

124 Siehe z.B. BGH, Urt. v. 30.04.2010, Az. I ZR 69/08, BGHZ 185, 291 Rn. 39 - Vorschaubilder; BGH, Urt. v. 19.03.2015, Az.: I ZR 94/13, NJW 2015, 3443 Rn. 42 - Hotelbewertungsportal.

125 Siehe z.B. BGH, Urt. v. 12.07.2007, Az. I ZR 18/04, BGHZ 173, 188 Rn. 53 - Jugendgefährdende Medien bei eBay; BGH, Urt. v. 17.08.2011, Az. I ZR 57/09, BGHZ 191, 19 Rn. 39 - Stiftparfüm; BGH, Urt. v. 12.07.2012, Az. I ZR 18/11, BGHZ 194, 39 Rn. 28 - Alone in the Dark; BGH, Urt. v. 19.03.2015, Az.: I ZR 94/13, NJW 2015, 3443 Rn. 42 - Hotelbewertungsportal; BGH, Urt. v. 26.11.2015, Az.: I ZR 3/14, NJW 2015, 28 Rn. 26 - Sperrung Access-Provider. 
Grundrechten vereinbar sein und ein angemessenes Gleichgewicht der widerstreitenden Rechte und Interessen sicherstellen. ${ }^{126}$

Abschließend ist darauf hinzuweisen, dass die Haftung des Internet-Diensteanbieters für rechtswidrige, durch Kommunikations-KI generierte Informationen unberührt bleibt. Dies dürfte in der Praxis vor allem bei Social Bots relevant sein, deren Betreiber nicht bekannt und/oder außerhalb eines Vollstreckungszugriffs im Ausland befindlich ist (und bei denen regelmäßig nicht einmal erkennbar ist, dass es sich überhaupt um einen Bot und nicht um einen Menschen handelt). Die Haftungs- und Überwachungspflichten von InternetDiensteanbietern bestimmen sich in diesen Fällen unverändert nach Art. 12 ff. e-commerceRichtlinie bzw. §§ 7 ff. TMG sowie spezialgesetzlichen Vorschriften, etwa nach dem Netzwerkdurchsetzungsgesetz. ${ }^{127}$

\section{f) Verschulden}

Während für einen Unterlassungsanspruch analog $\S \S 1004,823$ BGB ein drohender rechtswidriger Eingriff genügt, muss der Anbieter der KI für einen Schadensersatzanspruch des Betroffenen auch schuldhaft, d.h. vorsätzlich oder fahrlässig i.S.d. § 276 Abs. 2 BGB, gehandelt haben.

Ist die Rechtsverletzung bereits im Algorithmus angelegt (siehe unter c) aa)), liegt Vorsatz unproblematisch vor. Autonome (Fehl-)Entscheidungen einer KI sind hingegen qua Definition (siehe unter II. 3.) unvorhersehbar. Daher ließe sich argumentieren, dass eine Verschuldenshaftung für den Betrieb einer Kommunikations-KI - und dieser Gedanke ließe sich auf andere Formen schwacher KI übertragen - regelmäßig nicht gegeben ist. Diese vermeintliche Regelungslücke scheint dafür $\mathrm{zu}$ sprechen, de lege ferenda eine Gefährdungshaftung für KI einzuführen (dazu unter V. 2.).

Wie oben festgestellt, liegt der Vorwurf des pflichtwidrigen Verhaltens bei Kommunikations$\mathrm{KI}$ indessen nicht in dem Betrieb der $\mathrm{KI}$ als solcher, sondern in der Verletzung von Sorgfaltspflichten in Gestalt von Prüfungspflichten. Zwar kann auch dieser Nachweis im Einzelfall schwer zu führen sein. ${ }^{128}$ Etwaige Regelungslücken ließen sich hier jedoch mit einer Umkehr der Beweislast schließen (siehe unter V. 3.). Dabei wäre jedoch zunächst

\footnotetext{
${ }^{126}$ Vgl. EuGH, Rs. C-70/10 [2011] Scarlet Extended/SABAM u.a. [47-49]; Rs. C-360/10 [2012] SABAM/Netlog [44-47]; EuGH, Rs. C-314/12 [2014] UPC Telekabel Wien GmbH [46]; EuGH, Rs. C324/09 [2011] L'Oréal SA u.a./eBay International AG u.a. [143]; EuGH, Rs. C-484/14 [2016] McFadden [82 f.]; BGH, Urt. v. 26.11.2015, Az.: I ZR 3/14, NJW 2015, 28 Rn. 30 f. - Sperrung Access-Provider.

127 Gesetz zur Verbesserung der Rechtsdurchsetzung in sozialen Netzwerken (Netzwerkdurchsetzungsgesetz NetzDG) vom 1.9.2017, BGBl. 2017 I, S. 3352.

128 Vgl. Horner/Kaulartz, CR 2016, 7, 8; Grützmacher, CR 2016, 695, 696.
} 
sorgfältig zu prüfen, inwiefern hier überhaupt systemwidrige Regelungslücken bestehen. Eine Verletzung des allgemeinen Persönlichkeitsrechts begründet nach der Rechtsprechung des BGH einen Anspruch auf eine Geldentschädigung nur dann, wenn dies ,nach der Art der Verletzung des Persönlichkeitsrechts erforderlich“ ist, um dem Betroffenen „eine Genugtuung für die erlittene Unbill zuzusprechen“. ${ }^{129}$ Dies ist dann der Fall, wenn Einbußen auf andere Art nicht auszugleichen sind und es sich um eine schwere Verletzung des Persönlichkeitsrechts handelt. ${ }^{130}$ Indikatoren für die Schwere der Persönlichkeitsverletzung sind nicht nur die Auswirkungen der Persönlichkeitsverletzung auf den Betroffenen, wie etwa Nachhaltigkeit und Fortdauer einer Interessen- oder Rufschädigung des Verletzten. Zu berücksichtigen sind auch täterbezogene Faktoren wie Grad des Verschuldens und Anlass und Beweggrund des Handelns. ${ }^{131}$ Zugunsten des Deliktstäters kann jedoch ins Gewicht fallen, dass Vorwürfe zwar nicht erwiesen sind, aber auch nicht ausgeräumt werden konnten. ${ }^{132}$ Gegen eine besondere Schwere der Persönlichkeitsverletzung spricht etwa, wenn der Betroffene den sich Äußernden zu einer Entgegnung herausgefordert hat. ${ }^{133}$ Der Schadensersatzanspruch für Persönlichkeitsrechtsverletzungen ist nach dem BGH zudem subsidiär. Er entsteht nur dann, wenn ein Gegendarstellungs-, Unterlassungs- oder Widerrufsanspruch zur Wiederherstellung der persönlichen Integrität nicht möglich oder nicht ausreichend ist. ${ }^{134}$ Dies sei auch eine Ausprägung der Schadensminderungspflicht des Betroffenen nach $\S 254$ BGB. ${ }^{135}$ Bei Verletzungen von Persönlichkeitsrechten rücke „die

129 BGH, Urt. v. 19.09.1961, Az. VI ZR 259/60, BGHZ 35, 363, 369 - Ginsengwurzel; BGH, Urt. v. 07.01.1969, Az.: VI ZR 202/66, MDR 1969, 472 - Spielgefährtin II.

${ }^{130}$ BGH, Urt. v. 19.09.1961, Az. VI ZR 259/60, BGHZ 35, 363, 368 f. - Ginsengwurzel; BGH, Urt. v. 05.03.1963, Az. VI ZR 55/62, BGHZ 39, 124, 133 - Fernsehansagerin; BGH, Urt. v. 07.01.1969, Az.: VI ZR 202/66, MDR 1969, 472 - Spielgefährtin II; BGH, Urt. v. 17.03.1970, Az.: VI ZR 151/68, NJW 1970, 1077 f. - Nachtigall I; BGH, Urt. v. 25.05.1971, Az. VI ZR 26/70, VersR 1971, 845 - „Dreckschleuder“; BGH, Urt. v. 03.05.1977, Az. VI ZR 36/74, NJW 1977, 1288, 1290 - Abgeordnetenbestechung.

131 BGH, Urt. v. 19.09.1961, Az. VI ZR 259/6, BGHZ 35, 363, 369 - Ginsengwurzel; BGH, Urt. v. 05.03.1963, Az. VI ZR 55/62, BGHZ 39, 124, 130 - Fernsehansagerin; BGH, Urt. v. 25.05.1965, Az.: VI ZR 19/64, MDR 1965, 735 - „Wo ist mein Kind?“; BGH, Urt. v. 08.03.1966, Az. VI ZR 176/64, NJW 1966, 1213, 1215 - Luxemburger Wort; BGH, Urt. v. 07.01.1969, Az.: VI ZR 202/66, MDR 1969, 472 - Spielgefährtin II; BGH, Urt. v. 03.03.1970, Az.: VI ZR 115/68, MDR 1970, 579, 580 - Stadtdirektor; BGH, Urt. v. 25.05.1971, Az. VI ZR 26/70, VersR 1971, 845, 846 - „Dreckschleuder““ (insoweit nicht abgedruckt); BGH, Urt. v. 09.07.1985, Az. VI ZR 214/83, BGHZ 95, 212, 215 - Nachtigall II.

132 BGH, Urt. v. 09.07.1985, Az. VI ZR 214/83, BGHZ 95, 212, 215 - Nachtigall II; BGH, Urt. v. 30.01.1996, Az. VI ZR 386/94, BGHZ 132, 13, 27 - „Lohnkiller“.

${ }^{133}$ BGH, Urt. v. 25.05.1971, Az. VI ZR 26/70, VersR 1971, 845 f. - „Dreckschleuder“.

${ }^{134}$ Vgl. BGH, Urt. v. 19.09.1961, Az. VI ZR 259/60, BGHZ 35, 363, 369 - Ginsengwurzel; BGH, Urt. v. 12.10.1965, Az. VI ZR 95/64, NJW 1965, 2395, 2396 - „Mörder unter uns“; BGH, Urt. v. 29.10.1968, Az. VI ZR 180/66, GRUR 1969, 147, 149 f. - Korruptionsvorwurf; BGH, Urt. v. 17.03.1970, Az.: VI ZR 151/68, NJW 1970, 1077 f. - Nachtigall I; BGH, Urt, v. 06.04.1976, Az. VI ZR 246/74, NJW 1976, 1198,1201 Panorama; BVerfG, Beschl. v. 14.02.1973, Az. 1 BvR 112/65, BVerfGE 34, 269, 286 - Soraya.

135 BGH, Urt, v. 06.04.1976, Az. VI ZR 246/74, NJW 1976, 1198, 1201 - Panorama. 
Genugtuungsfunktion des Schmerzensgeldes gegenüber der Entschädigungsfunktion durchaus in den Vordergrund.“136 Daher ist es folgerichtig, einen Entschädigungsanspruch dann auszuschließen, wenn dieser Funktion bereits durch einen anderen Anspruch genügt wird, etwa einer Widerrufserklärung oder einer Gegendarstellung. Dies harmoniert mit dem Zweck der Geldentschädigung, eine Lücke im Schutz der Persönlichkeit zu schließen. Wird dieser Zweck anderweitig oder kann er nicht mehr erfüllt werden, bedarf es der Entschädigung als ultima ratio nicht mehr. Einen vollstreckbaren Unterlassungs- oder Widerrufsanspruch betrachten BGH und BVerfG als grundsätzlich geeignet, die Persönlichkeitsverletzung abzumildern. ${ }^{137}$ Es ist daher möglich, dass einem Betroffenen ein Anspruch auf Unterlassung oder Widerruf zusteht, nicht aber auf Schadensersatz. ${ }^{138}$ Nur ausnahmsweise und unter besonderen Umständen kann eine erlittene Beeinträchtigung allein durch eine Entschädigung in Geld ausgeglichen werden. ${ }^{139}$

Diese Sonderdogmatik der Persönlichkeitsrechte zeigt wiederum, wie wichtig es ist, zwischen verschiedenen Erscheinungsformen schwacher KI zu unterscheiden. Anders als etwa bei selbstfahrenden Autos oder Haushaltsrobotern dürfte der praktische Schwerpunkt der Haftung für Kommunikations-KI in der Störerhaftung liegen, nicht in der deliktischen Verschuldenshaftung.

\section{Haftung nach $§ 823$ Abs. 2 BGB i.V.m. $§ 185$ ff. StGB}

Bei Ehrverletzungen kommt zudem eine Haftung nach $\S 823$ Abs. 2 BGB i.V.m. §§ 185 ff. StGB in Betracht. Auch hier ist sorgfältig zwischen der - in diesem Fall strafrechtlichen Haftung der KI selbst und der Haftung des Anbieters bzw. Herstellers der KI zu unterscheiden. Eine strafrechtliche Verantwortung der KI selbst kommt nicht in Betracht, da das deutsche Strafrecht nur auf menschliches Verhalten (Tun oder Unterlassen) Anwendung findet. ${ }^{140}$ Sieht man einmal von den Fällen ab, in denen die Rechtsverletzung bewusst im Algorithmus angelegt ist (dazu unter 2. c) aa)), dürfte es für den Anbieter bzw. Hersteller

136 BGH, Urt. v. 19.09.1961, Az. VI ZR 259/60, BGHZ 35, 363, 369 - Ginsengwurzel m.w.N.

137 BVerfG, Beschl. v. 13.03.2007, Az. 1 BvR 1377/04, NJW-RR 2007, 1194 f.- Veronica Ferres; BGH, Urt. v. 29.10.1968, Az. VI ZR 180/66, GRUR 1969, 147, 150 - Korruptionsvorwurf Rn. 37; BGH, Urt. v. 24.05.2016, Az. VI ZR 496/15, CR 2016, 94 - „Schweinebacke“.

138 Vgl. BGH, Urt. v. 17.03.1970, Az.: VI ZR 151/68, NJW 1970, 1077 f. - Nachtigall I; BVerfG, Beschl. v. 02.04.2017, Az. 1 BvR 2194/15, AfP 2017, 228 Rn. 12 - „Luder vom Lerchenberg“.

139 BGH, Urt. v. 29.10.1968, Az. VI ZR 180/66, GRUR 1969, 147, 150 - Korruptionsvorwurf; BGH, Urt. v. 17.03.1970, Az.: VI ZR 151/68, NJW 1970, 1077, 1078 - Nachtigall I.

140 Joerden, in: Hilgendorf/Günther (Hrsg.), Robotik und Gesetzgebung, 2013, 195; Gleß/Weigend, ZStW 126 (2014), 561, 566; Seher, in: Gless/Seelmann (Hrsg.), Intelligente Agenten und das Recht, 2016, 45; Volkmann, MMR 2018, 58, 60. 
einer Kommunikations-KI regelmäßig am Vorsatz i.S.d. § 15 StGB fehlen. Ob im Einzelfall Eventualvorsatz in Betracht kommt, ist Tatfrage.

$\S 193$ StGB statuiert einen besonderen Rechtfertigungsgrund insbesondere für Äußerungen, welche zur Wahrnehmung berechtigter Interessen gemacht werden. Diese Vorschrift gilt allerdings nur für Beleidigung und üble Nachrede, nicht jedoch für Verleumdung. ${ }^{141}$ Ähnlich wie die Prüfung der Rechtswidrigkeit einer Verletzung des allgemeinen Persönlichkeitsrechts stellt $\S 193$ StGB ein „Einfallstor“ für die grundrechtlich gebotene Abwägung widerstreitender Interessen dar.

\section{Haftung nach $\$ 824$ BGB}

Für eine Verletzung der sog. „Geschäftsehre“ nach § 824 BGB stellen sich ähnliche Probleme wie zu $\S 823$ Abs. 1 und Abs. 2 BGB. Positive Kenntnis des Anbieters oder Herstellers einer Kommunikations-KI, die unwahre geschäftsschädigende Tatsachen i.S.d. § 824 Abs. 1 BGB verbreitet, kommt nur dann in Betracht, wenn diese Behauptungen im Algorithmus selbst angelegt sind. Bei einer KI, die die unwahre Tatsache erst „gelernt“ hat und dann verbreitet, kommt allenfalls fahrlässige Unkenntnis in Betracht. Lässt sich auch eine fahrlässige Unkenntnis nicht nachweisen, so ist der Anbieter oder Hersteller nicht zum Schadensersatz verpflichtet, wenn er oder der Empfänger der Mitteilung an ihr ein berechtigtes Interesse hatte ( 824 Abs. 2 BGB). Für die nach $\S 824$ Abs. 2 BGB erforderliche Abwägung gelten ähnliche Maßstäbe wie im Rahmen der Rechtswidrigkeit einer Verletzung des allgemeinen Persönlichkeitsrechts bzw. einer Rechtfertigung nach § 193 StGB. Abwägungsfaktoren sind der Grad des öffentlichen Interesses an dem Thema, der Grad des geschäftsschädigenden Gehalts der Äußerung und die Wahrung der Sorgfaltspflichten. ${ }^{142}$ Im Mittelpunkt steht auch hier wieder die Frage, inwieweit sich Anbieter von Kommunikations-KI auf die Kommunikationsgrundrechte berufen können (dazu unter 2. d)). Die Wertungen der Art. 14 und 15 e-commerce Richtlinie, $\S 7$ Abs. 2 Satz 1, 10 TMG sollten auch hier entsprechend herangezogen werden.

\section{Datenschutzrechtliche Haftung}

\footnotetext{
141 Vgl. BGH, Urt. v. 15.11.1977, Az.: VI ZR 101/76, NJW 1978, 210 - Alkoholtest; BGH, Urt. v. 12.02.1985, Az. VI ZR 225/83, NJW 1985, 1621, 1623 - Türkeiflug I.

${ }^{142}$ Vgl. BGH, Urt. v. 21.06.1966, Az. VI ZR 266/64, NJW 1966, 2010, 2011 f. - Teppichkehrmaschine.
} 
KI-Kommunikation ist „datazentrische“, nicht „homozentrische“ Kommunikation. ${ }^{143}$ Dem Datenschutzrecht kommt bei Kommunikations-KI daher eine besondere Bedeutung zu, die über die allgemeinen datenschutzrechtlichen Herausforderungen von KI und Big Data, etwa bei selbstfahrenden Fahrzeugen, weit hinausgeht. ${ }^{144}$ Das Kommunikationsdeliktsrecht betrifft Delikte, die durch die Kommunikation von Informationen begangen werden. „Informationen“ sind Daten, denen eine Bedeutung zukommt. ${ }^{145}$ Für die hergebrachten zivilrechtlichen Ansprüche - Unterlassung, Widerruf, Schadensersatz etc. - sind Informationen allein in ihrer semantischen Dimension relevant, d.h. weil ihnen eine bestimmte - etwa ehrenrührige Bedeutung zukommt. Unbeachtlich ist demgegenüber die syntaktische Dimension der Information, d.h. ihre Verkörperung als Datum. Einen anderen Ansatz wählt das Datenschutzrecht. Ausgangspunkt des Datenschutzrechts ist nicht die semantische Dimension der Information, sondern ihre syntaktische. Mit anderen Worten: Ausgangspunkt des Datenschutzrechts ist die Eigenschaft einer Information als (personenbezogenes) Datum. Anders als im hergebrachten Kommunikationsdeliktsrecht kommt es für den Datenschutz grundsätzlich nicht darauf an, ob ein personenbezogenes Datum Persönlichkeitsrechte verletzt oder in sonstiger Weise für die betroffene Person nachteilig ist. ${ }^{146}$ Da personenbezogene Daten jedoch auch persönlichkeitsrechtsverletzende Daten sein können, ist das Datenschutzrecht angesichts der zunehmenden Digitalisierung und Datafizierung ein bedeutsames Instrument auch zum Schutz der Persönlichkeitsrechte geworden.

Das Recht auf Schutz personenbezogener Daten umfasst das Recht, grundsätzlich selbst darüber zu bestimmen, ob, wann und in welchem Ausmaß personenbezogene Daten erhoben, gespeichert, verarbeitet und veröffentlicht werden. ${ }^{147}$ Es ist in Art. 8 EUGRCh ausdrücklich kodifiziert, aber auch unter Art. 10 EMRK und Art. 2 Abs. 1 i.V.m. Art. 1 Abs. 1 GG

${ }^{143}$ Antos, Zeitschrift für germanistische Linguistik 45 (2017), 392, 398.

${ }^{144}$ Dazu etwa Haustein, in: Hilgendorf/Günther (Hrsg.), Robotik und Gesetzgebung, 2013, 93 ff.; Schulz, Verantwortlichkeit bei autonom agierenden Systemen, 2015, S. 200 ff.; Franck/Müller-Peltzer, DSRITB 2017, 241, 248 ff.; Conrad, DuD 2017, 740.

${ }^{145}$ Floridi, The Philosophy of Information, 2011, S. 83.

146 EuGH, verb. Rs. C-465/00, C-138/01 und C-139/01 [2003] Rechnungshof/Österreichischer Rundfunk u.a. [73-75]; verb. Rs. C-293/12 und C-594/12 [2014] Digital Rights Ireland Ltd und Kärntner Landesregierung [33]; verb. Rs. C-92/09 und C-93/09 [2010] Volker und Markus Schecke GbR und Hartmut Eifert [59-60]; mutatis mutandis Rs. T-194/04 [2007] Bavarian Lager [119]; vgl. EGMR, Niemietz/Deutschland [1992] Beschwerde-Nr. 13710/88 [29].

147 Grundlegend BVerfG, Urt. v. 15.12.1983, Az. 1 BvR 209/83 u.a., BVerfGE 65, 1 - Volkszählungsurteil; BGH, Urt. v. 23.09.2014, Az. VI ZR 358/13, NJW 2015, 489 Rn. 26 - Ärztebewertung II; EGMR, Amann/Schweiz [2000] Beschwerde-Nr. 27798/95 [65]. 
anerkannt. $^{148}$ Die am 25. Mai 2018 zur Anwendung gekommene DatenschutzGrundverordnung (DSGVO) stattet betroffene Personen mit einer Reihe von Rechten aus, deren Verletzung Ansprüche auf Schadensersatz auslösen kann. ${ }^{149}$ Sie werden flankiert durch entsprechende Informations- und Auskunftsansprüche. ${ }^{150}$ Besondere Bedeutung für Kommunikations-KI dürften dem Recht auf Berichtigung nach Art. 16 DSGVO und dem „Recht auf Vergessenwerden“ nach Art. 17 DSGVO zukommen. ${ }^{151}$

Anders als andere Formen schwacher KI betreibt Kommunikations-KI nicht nur den Austausch und die Generierung neuer (auch personenbezogener) Daten ${ }^{152}$, sondern sie kommuniziert diese Daten an die Öffentlichkeit oder an eine bestimmte Personengruppe. Im Bereich der Kommunikations-KI sind datenschutzrechtliche Rechtsbehelfe daher nicht nur dazu geeignet, eine Verletzung des Rechts auf informationelle Selbstbestimmung zu beheben, was der eigentliche Zweck des Datenschutzrechts ist. Das Datenschutzrecht ist zugleich ein Instrument, um über die informationelle Selbstbestimmung hinausgehende Rechte, z.B. die persönliche Ehre, zu schützen: Ist die Verarbeitung personenbezogener, ehrenrühriger Daten unterbunden, so ist auch die Ehrverletzung beendet. ${ }^{153}$ Angesichts der Digitalisierung und Datafizierung der Kommunikation dürfte das scharfe Datenschutzrecht damit die hergebrachten Rechtsbehelfe zum Persönlichkeitsschutz zunehmend ersetzen. Dies wird auch die Haftung für Kommunikations-KI maßgeblich prägen. Entscheidende Bedeutung wird daher in jedem Einzelfall der Frage zukommen, ob durch Kommunikations-KI verarbeitete Informationen personenbezogene Daten i.S.d. Art. 4 Nr. 1 DSGVO darstellen. ${ }^{154} \mathrm{Zu}$ klären

148 Siehe etwa EKomMR, X/Vereinigtes Königreich [1982] Beschwerde-Nr. 9702/82; EGMR, Leander/Schweden [1987] Beschwerde-Nr. 9248/81 [59] und [67]; Amann/Schweiz [2000] Beschwerde-Nr. 27798/95 [67]; Rotaru/Rumänien [2000] Beschwerde-Nr. 28341/95 [43]; Segerstedt-Wiberg u.a./Schweden [2006] Beschwerde-Nr. 62332/00; S. und Marper/Vereinigtes Königreich [2008] Beschwerde-Nr. 30562/04 und 30566/04; Biriuk/Litauen [2008] Beschwerde-Nr. 23373/03 [39]; I/Finnland [2008] Beschwerde-Nr. 20511/03 [38]; Z/Finnland [1997] Beschwerde-Nr. 22009/93 [96].

149 Art. 12 ff., Art. 77 ff. DSGVO.

150 Siehe Art. 8 Abs. 2 Satz 2 EUGRCh und Art. 14 und 15 DSGVO; EuGH, Rs. C-553/07 [2009] College van burgemeester en wethouders van Rotterdam v. M.E.E. Rijkeboer.

151 Vgl. EuGH, Rs. C-131/12 [2014] Google Spain SL und Google Inc./AEPD u.a.; BGH, Urt. v. 28.07.2015, Az. VI ZR 340/14, NJW 2016, 56 Rn. 31 - recht§billig. Grundlegend zum „Recht auf Vergessenwerden“ Mayer-Schönberger, Delete: the virtue of forgetting in the digital age, 2009.

152 Vgl. Stiemerling, CR 2015, 762, 765.

153 Siehe z.B. BGH, Urt. v. 23.06.2009, Az. VI ZR 196/08, BGHZ 181, 328 Rn. 17 m.w.N. - spickmich.de; BGH, Urt. v. 23.09.2014, Az. VI ZR 358/13, NJW 2015, 489 Rn. 28 - Ärztebewertung II; BGH, Urt. v. 28.07.2015, Az. VI ZR 340/14, NJW 2016, 56 Rn. 13 - recht§billig

${ }^{154}$ Dazu ausführlich Oster, European and International Media Law, 2017, S. 325 ff.; Oster, in: Hartstein u.a. (Hrsg.), Heidelberger Kommentar zum Rundfunkstaatsvertrag und zum Jugendmedienschutz-Staatsvertrag, 74. AL Juni 2018, § 9c RStV Rn. 16 ff. 
wird insbesondere sein, inwieweit sich ein Betreiber von algorithmischem Journalismus auf das sog. „Medienprivileg“ des Art. 85 Abs. 2 DSGVO berufen kann. ${ }^{155}$

\section{Haftung für Kommunikations-KI de lege ferenda}

Wie die Haftung für Kommunikations-KI de lege ferenda auszugestalten ist, rührt an die Grundfragen des Deliktsrecht: Was ist Aufgabe und Ziel des Deliktsrechts? Das deutsche Deliktsrecht beruht vorrangig auf dem sog. Kompensationsmodell. Ziel des Deliktsrechts ist es danach, eine mögliche Besserstellung des Deliktstäters zu beenden und den Betroffenen für den ihm zugefügten Nachteil zu entschädigen, d.h. seine Schlechterstellung auszugleichen. ${ }^{156}$ Zwischen Störung und Ausgleich muss eine Äquivalenzbeziehung bestehen. ${ }^{157}$ In persönlicher Hinsicht ist auf die am Prozess beteiligten Individuen und in sachlicher Hinsicht auf deren Verhalten in der Vergangenheit abzustellen. Eine Bereicherung des Deliktsopfers ist ebenso unzulässig wie eine Belastung des Deliktstäters, die über die Vergeltung des Delikts hinausgeht. ${ }^{158}$ Zwar kommt dem Anspruch auf Geldentschädigung auch eine präventive Wirkung zu, indem sie unerlaubte Handlungen einem finanziellen Risiko unterwirft. ${ }^{159}$ Nach dem BGH muss in Fällen, in denen der Deliktstäter aus der Persönlichkeitsrechtsverletzung einen Gewinn erzielte, von der Höhe der Geldentschädigung „ein echter Hemmungseffekt“ ausgehen. ${ }^{160}$ Da hiermit jedoch zugleich ein Einschüchterungseffekt verbunden ist, unterliegt

155 Zum „Medienprivileg“ EuGH, Rs. C-73/07 [2008] Satakunnan Markkinapörssi Oy und Satamedia Oy [61]; EGMR, Satakunnan Markkinapörssi Oy und Satamedia Oy/Finnland [2017] Beschwerde-Nr. $931 / 13$ [150]; BGH, Urt. v. 23.06.2009, Az. VI ZR 196/08, BGHZ 181, 328 Rn. 19 - spickmich.de; BGH, Urt. v. 23.09.2014, Az. VI ZR 358/13, NJW 2015, 489 Rn. 40 - Ärztebewertung II; Oster, in: Hartstein u.a. (Hrsg.), Heidelberger Kommentar zum Rundfunkstaatsvertrag und zum Jugendmedienschutz-Staatsvertrag, 74. AL Juni 2018, § 9c RStV Rn. 34 ff.

${ }^{156}$ Dazu und zu den in Einzelheiten bestehenden Meinungsverschiedenheiten etwa Coleman, Journal of Legal Studies 11 (1982), 421; Weinrib, Iowa Law Review 77 (1992), 403; Coleman, Indiana Law Review 67 (1992), 349; Coleman, Iowa Law Review 77 (1992), 427; Rohe, AcP 201 (2001), 117, 124 ff.; Hershovitz, Stanford Law Review 63 (2010), 67, 106 ff.; Gardner, Law \& Philosophy 2011, 1; Al-Tawil, European Journal of Legal Studies, 6 (2013), 109, 112 ff.

157 Vgl. Ulpian, Dig. 1.1.10pr: „Iuris praecepta sunt haec: honeste vivere, alterum non laedere, suum cuique tribuere.“; Mahlmann, Rechtsphilosophie und Rechtstheorie, 3. Aufl. 2014, § 27 Rn. 17.

158 BGH, Urt. v. 17.06.1953, Az. VI ZR 51/52, BGHZ 10, 104, 106 - Eiprodukten-Einfuhrverband.

159 BVerfG, Beschl. v. 13.05.1980, Az. 1 BvR 103/77, BVerfGE 54, 129, 136 - Kunstkritik; Vgl. BGH, Urt. v. 07.12.1976, Az. VI ZR 272/75, NJW 1977, 626, 628 - Aktion Soziale Marktwirtschaft; BGH, Urt. v. 05.10.2004, Az. VI ZR 255/03, BGHZ 160, 298, 302, 307 - Alexandra von Hannover; BGH, Urt. v. 17.12.2013, Az. VI ZR 211/12, NJW 2014, 6 Rn. 49 - Sächsische Korruptionsaffäre.

160 BGH, Urt. v. 15.11.1994, Az. VI ZR 56/94, BGHZ 128, 1, 16 - Erfundenes Exklusiv-Interview; BGH, Urt. v. 05.12.1995, Az. VI ZR 332/94, NJW 1996, 984, 985 - Caroline von Monaco I; BGH, Urt. v. 05.10.2004, Az. VI ZR 255/03, BGHZ 160, 298, 307 - Alexandra von Hannover; BGH, Urt. v. 17.12.2013, Az. VI ZR 211/12, NJW 2014, 6 Rn. 49 - Sächsische Korruptionsaffäre. 
die Höhe des Entschädigungsanspruchs strengen verfassungsrechtlichen Anforderungen. ${ }^{161}$ Insbesondere habe eine Entschädigung wegen einer Verletzung von Persönlichkeitsrechten keinen Strafcharakter i.S.d. Art. 103 Abs. 2 GG, so der BGH. ${ }^{162}$ Die Entschädigung für Persönlichkeitsverletzungen dürfe nicht dazu dienen, eine Bestrafung des Deliktstäters über das Zivilrecht durchzusetzen. ${ }^{163}$ Dies entspricht auch der Rechtsprechung des EGMR. Nach dem EGMR dürfen Gerichte die Wahrnehmung der Kommunikationsgrundrechte keinen unvorhersehbaren oder unverhältnismäßigen Haftungsrisiken aussetzen; insbesondere ist zu vermeiden, dass die Sanktionen einschüchternde Wirkungen entfalten. Die Höhe der Entschädigung muss in einem „vernünftigen Verhältnis“ zu der Persönlichkeitsrechtsverletzung stehen. ${ }^{164}$

Kehrseite dieser Kompensationsgrenzen ist die Risikozuweisungsfunktion des Deliktsrechts. Indem es eine Kompensation für Schäden vorsieht, die durch unerlaubte Handlungen herbeigeführt wurden, weist das Deliktsrecht potenziellen Schädigern Risiken zu. Zugleich weist es aber auch potenziellen Opfern Risiken zu, da diese Kompensation nur unter bestimmten Voraussetzungen und nur innerhalb bestimmter Grenzen erfolgt. Insbesondere besteht kein allgemeines Verbot, andere nicht zu gefährden. ${ }^{165}$

Die sog. Genugtuungsfunktion ist zwar allenfalls eine Nebenfunktion des Deliktsrechts. Ein deliktsrechtlicher Schadensersatzanspruch rechtfertigt sich danach nur in besonderen Fällen aus der Notwendigkeit einer Genugtuung für das Opfer. Ein solcher besonderer Fall liegt jedoch gerade bei der Verletzung des Allgemeinen Persönlichkeitsrechts vor. ${ }^{166}$ Der verletzten

161 Vgl. BVerfG, Beschl. v. 14.02.1973, Az. 1 BvR 112/65, BVerfGE 34, 269, 285 f. - Soraya; BVerfG, Beschl. v. 13.03.2007, Az. 1 BvR 1377/04, NJW-RR 2007, 1194 - Veronica Ferres.

162 BGH, Urt. v. 05.10.2004, Az. VI ZR 255/03, BGHZ 160, 298, 302 f. - Alexandra von Hannover. Kritisch Gounalakis/Rösler, Ehre, Meinung und Chancengleichheit im Kommunikationsprozeß, 1998, S. 97 f.; Gounalakis, AfP 1998, 10, 14 ff.; Seitz, NJW 1996, 2848, 2849 f.; Funkel, Schutz der Persönlichkeit durch Ersatz immaterieller Schäden in Geld, 2001, S. 164 ff.

${ }^{163}$ BGH, Urt. v. 07.12.1976, Az. VI ZR 272/75, NJW 1977, 626, 628 - Aktion Soziale Marktwirtschaft; s.a. für das IPR Art. 40 Abs. 3 Nr. 1 und 2 EGBGB und für das IZVR BGH, Urt. v. 04.06.1992, Az.: IX ZR 149/91, BGHZ 118, 312 - Punitive damages.

${ }^{164}$ EGMR, Tolstoy Miloslavsky/Vereinigtes Königreich [1995] Beschwerde-Nr. 18139/91 [49]; Steel und Morris/Vereinigtes Königreich [2005] Beschwerde-Nr. 68416/01 [96]; Independent News und Media/Irland [2005] Beschwerde-Nr. 55120/00 [110]: ,an award of damages for defamation must bear a reasonable relationship of proportionality to the injury to reputation suffered“; zuletzt bestätigt in Independent Newspapers (Ireland) Limited/Irland [2017] Beschwerde-Nr. 28199/15 [92].

165 BGH, Urt. v. 09.09.2008, Az. VI ZR 279/06, NJW 2008, 3778 Rn. 11 - Quad; Rohe, AcP 201 (2001), 117, 123.

166 BGH, Urt. v. 19.09.1961, Az. VI ZR 259/60, BGHZ 35, 363, 369 - Ginsengwurzel; BGH, Urt. v. 08.07.1980, Az.: VI ZR 177/78, BGHZ 78, 24, 28 - „Medizin-Syndikat“ I; vgl. BGH, Urt. v. 14.02.1958, Az. I ZR 151/56, BGHZ 26, 349, 358 - Herrenreiter; BGH, Urt. v. 25.05.1965, Az.: VI ZR 19/64, MDR 1965, 735 - „Wo ist mein Kind?“; BGH, Urt. v. 05.10.2004, Az. VI ZR 255/03, BGHZ 160, 298, 302 - Alexandra von Hannover; BGH, Urt. v. 24.05.2016, Az. VI ZR 496/15, CR 2016, 94 - „Schweinebacke“. 
Persönlichkeit soll gemäß $\S 823$ Abs. 1 BGB i.V.m. Art. 1 und 2 GG „Genugtuung“ verschafft werden, indem ,eine mit anderen Rechtsbehelfen nicht überbrückbare Lücke im Schutz der Persönlichkeit" geschlossen wird. ${ }^{167}$

Vor dem Hintergrund dieser Funktionen des Deliktsrechts im Allgemeinen und des Persönlichkeitsschutzes im Besonderen sind vorgeschlagene Haftungsmodelle für KI danach $\mathrm{zu}$ untersuchen, ob sie auf Persönlichkeitsrechtsverletzungen durch Kommunikations-KI Anwendung finden sollten.

\section{Haftung der KI selbst}

Angestoßen von Informatikern wird in der internationalen rechtswissenschaftlichen Literatur derzeit ein Vorschlag diskutiert, der nicht nur das deutsche Deliktsrecht, sondern auch etwa das Vertragsrecht, das Strafrecht und die Grundrechtsdogmatik grundlegend herausfordert. Dies ist der Gedanke, einer KI selbst Rechtsfähigkeit, etwa als „elektronische Person“, zuzugestehen und damit eine eigenständige Haftung der KI zu begründen. ${ }^{168}$ Da eine KI kein eigenes Vermögen hat, ließe sich die Haftung der KI etwa mittels einer Versicherungspflicht oder eines Haftungsfonds umsetzen.

Entscheidend für die Antwort auf die Frage, ob und inwieweit eine KI Rechtsfähigkeit besitzen sollte oder nicht, ist der Ausgangspunkt, von dem aus ein solcher Diskurs geführt wird. Von Seiten der Informatik wird in diesem Zusammenhang das Argument - oder eher der Kampfbegriff - des carbon bias angeführt: Wer hinsichtlich der Rechtsfähigkeit von KI und Menschen unterscheide, der diskriminiere nur aufgrund der physischen Beschaffenheit, nämlich Kohlenstoff (Mensch) und Silikon (Maschine), aber ohne rechtfertigende Gründe. In Teilen hat sich die rechtswissenschaftliche Diskussion daher die Ausgangsfragestellung des carbon bias aufzwingen lassen: „Warum sollte man einer KI - im Unterschied zum Menschen oder zu juristischen Personen - keine Rechtsfähigkeit zubilligen?“169 Legt man diese Frage

${ }^{167}$ BGH, Urt. v. 08.07.1980, Az.: VI ZR 177/78, BGHZ 78, 24, 28 - „Medizin-Syndikat“ I; vgl. BGH, Urt. v. 14.02.1958, Az. I ZR 151/56, BGHZ 26, 349, 358 - Herrenreiter; BGH, Urt. v. 19.09.1961, Az. VI ZR 259/60, BGHZ 35, 363, 369 - Ginsengwurzel; BGH, Urt. v. 25.05.1965, Az.: VI ZR 19/64, MDR 1965, 735 - „Wo ist mein Kind?“; BGH, Urt. v. 05.10.2004, Az. VI ZR 255/03, BGHZ 160, 298, 302 - Alexandra von Hannover; BGH, Urt. v. 24.05.2016, Az. VI ZR 496/15, CR 2016, 94 - „Schweinebacke“.

168 Grundlegend Solum, North Carolina Law Review 70 (1992), 1231; siehe etwa Wettig/Zehendner, Artificial Intelligence and Law 12 (2004), 111; Koops/Hildebrandt/Jaquet-Chiffelle, Minnesota Journal of Law, Science \& Technology 11 (2010), 497; Beck, in: Hilgendorf/Günther (Hrsg.), Robotik und Gesetzgebung, 2013, 239; Vladeck, Washington Law Review 89 (2014), 117; Primo/Zago, Digital Journalism 3 (2015), 38; Kersten, JZ 2015, 1, 7; Reichwald/Pfisterer, CR 2016, 208, 2012; Kluge/Müller, DSRITB 2016, 989; Schaub, JZ 2017, 342, $345 \mathrm{f}$.

169 Vgl. Wettig/Zehendner, Artificial Intelligence and Law 12 (2004), 111, 124; Beck, JR 2009, 225, 229; Koops/Hildebrandt/Jaquet-Chiffelle, Minnesota Journal of Law, Science \& Technology 11 (2010), 497, 527; 
zugrunde, so befinden sich potenzielle Gegner einer Rechtsfähigkeit von KI in der Defensive. Sie müssen mit philosophischen Argumenten ${ }^{170}$ und unter Berücksichtigung der Erkenntnisse der Hirnforschung ${ }^{171}$ erläutern, was „Leben“ ist und was den Menschen von KI (noch) unterscheidet. ${ }^{172}$ Selbst wenn diese Argumentation gelingt, können Befürworter einer Rechtsfähigkeit von KI der Gegenseite immer noch den naturalistischen Fehlschluss entgegenhalten: Die Tatsache, dass es gute Gründe für die Rechtsfähigkeit natürlicher Personen gibt, erlaubt nicht die Schlussfolgerung, dass KI keine Rechtsfähigkeit zugestanden werden sollte. ${ }^{173}$ Einzuräumen ist auch, dass Mensch und Technologie schon immer symbiotisch gewesen sind und zunehmend hybridisieren; angefangen bei Kleidungsstücken über Brillen und Hörgeräte bis hin zu Herzschrittmachern, künstlicher Beatmung und Tiefer Hirnsimulation. ${ }^{174}$ Schließlich wird für eine Rechtsfähigkeit von Maschinen das dritte Asimovsche Robotergesetz angeführt. ${ }^{175}$

Sachgerechter ist indessen, die Debatte unter einem entgegengesetzten Vorzeichen zu führen: „Warum sollte einer KI Rechtsfähigkeit zugebilligt werden?“ Diese Fragestellung spiegelt die Tatsache wider, dass Rechtsfähigkeit kein natürliches, sondern ein juristisches Konstrukt ist, über das die Rechtsordnung entscheidet. Dass der Gesetzgeber natürlichen Personen Rechtsfähigkeit zubilligt ( $§ 1 \mathrm{BGB}$ ), ist historisch hergebracht ${ }^{176}$ und von Art. 1 Abs. 1 GG

Čerka/Grigienè/Sirbikyte, Computer Law \& Security Review 33 (2017), 685, 692; Hage, Artificial Intelligence and Law 25 (2017), 255, 270; Tegmark, Life 3.0, 2017, S. 109.

170 Vgl. Matthias, Automaten als Träger von Rechten, 2008, S. 45 ff.; Gleß/Weigend, ZStW 126 (2014), 561, 569 f.; Erhardt/Mona, in: Gless/Seelmann (Hrsg.), Intelligente Agenten und das Recht, 2016, 61; Čerka/Grigienè/Sirbikytè, Computer Law \& Security Review 33 (2017), 685, 691 ff.; Brożek/Jakubiec, Artificial Intelligence and Law 25 (2017), 293, 303.

171 Vgl. Beck, JR 2009, 225, 229 f. m.w.N.; Gleß/Weigend, ZStW 126 (2014), 561, 574 m.w.N.

172 Vgl. Beck, JR 2009, 225, 229; Müller-Hengstenberg/Kirn, MMR 2014, 307; Gleß/Weigend, ZStW 126 (2014), 561, 588 f.; Solaiman, Artificial Intelligence and Law 25 (2017), 155. Der KI-Forscher Max Tegmark etwa definiert „Leben“ als Prozess der Eigenreproduktion von Informationen (Tegmark, Life 3.0, 2017, S. 25). Nach dieser Definition würde auch KI ,leben“.

173 Vgl. Kersten, JZ 2015, 1, 7; Schirmer, JZ 2016, 660, 662.

174 Beck, JR 2009, 225, 228; Koops/Hildebrandt/Jaquet-Chiffelle, Minnesota Journal of Law, Science \& Technology 11 (2010), 497, 526; Hanisch, in: Hilgendorf (Hrsg.), Robotik im Kontext von Recht und Moral, 2014, 27, 44 .

175 Kersten, JZ 2015, 1, 7. Der Science Fiction-Autor Isaac Asimov beschrieb in seiner Kurzgeschichte Runaround (1942) erstmals die „Drei Robotergesetze“ (Three Laws of Robotics):

„1. Ein Roboter darf kein menschliches Wesen verletzen oder durch Untätigkeit zulassen, dass einem menschlichen Wesen Schaden zugefügt wird.

2. Ein Roboter muss den ihm von einem Menschen gegebenen Befehlen gehorchen - es sei denn, ein solcher Befehl würde mit Regel eins kollidieren.

3. Ein Roboter muss seine Existenz beschützen, solange dieser Schutz nicht mit Regel eins oder zwei kollidiert."

(Übersetzung nach https://de.wikipedia.org/wiki/Robotergesetze).

176 Vgl. Savigny, System des heutigen römischen Rechts, Bd. 2, 1840, S. 2: „Jeder einzelne Mensch, und nur der einzelne Mensch, ist rechtsfähig“; Locke, An Essay Concerning Human Understanding, 1690, 2. Buch, 27. 
geboten. ${ }^{177}$ Dass der Gesetzgeber juristischen Personen und Personenvereinigungen (Teil)Rechtsfähigkeit einräumt, hat funktionale Gründe: Es dient der Vereinfachung einer Vielzahl von Transaktionen. ${ }^{178}$ Hinsichtlich der Grundrechtsfähigkeit juristischer Personen (Art. 19 Abs. 3 GG) ist zudem anzumerken, dass diese sich nicht uneingeschränkt auf Grundrechte berufen können, sondern nach Art. 19 Abs. 3 GG nur, ,soweit sie [d.h. die Grundrechte] ihrem Wesen nach“ auf juristische Personen anwendbar sind. Das BVerfG legt diese Voraussetzung für die Grundrechtsfähigkeit juristischer Personen so aus, dass eine Einbeziehung juristischer Personen in den Schutzbereich der Grundrechte nur dann gerechtfertigt ist, ,wenn ihre Bildung und Betätigung Ausdruck der freien Entfaltung der natürlichen Personen sind, besonders wenn der ,Durchgriff‘ auf die hinter den juristischen Personen stehenden Menschen dies als sinnvoll oder erforderlich erscheinen läßt.“"179 Die Grundrechtsfähigkeit juristischer Personen ist nach dem BVerfG somit anthropozentrisch begründet. ${ }^{180}$ Schließlich lässt sich auch Befürwortern einer Rechtsfähigkeit von KI der naturalistische Fehlschluss entgegenhalten: Die Tatsache, dass KI in bestimmten Bereichen dem Menschen ähnlicher wird und diesem sogar überlegen ist, lässt nicht den Schluss zu, dass KI deswegen Rechtsfähigkeit gewährt werden sollte. Entscheidend ist vielmehr, inwiefern es - ähnlich wie bei einer juristischen Person oder Personenvereinigung - funktionale Gründe dafür gibt, KI Rechtsfähigkeit zuzugestehen. ${ }^{181}$ Nach dem hier vertretenen Ansatz ist es indessen nicht zielführend, diese Frage für KI als solche stellen, sondern für jede einzelne Form schwacher KI im Einzelfall. ${ }^{182}$ So mag es Gründe dafür geben, einer KI, die autonom

Kapitel, § 26: „[Person] belongs only to intelligent agents, capable of a law, and happiness and misery. This personality extends itself beyond present existence to what is past, only by consciousness, whereby it becomes concerned and accountable, owns and imputes to itself past actions.".

177 Müller-Hengstenberg/Kirn, MMR 2014, 307 f.; Schulz, Verantwortlichkeit bei autonom agierenden Systemen, 2015, S. 91; Taeger, NJW 2016, 3764, 3765. Dazu bereits Kant, Kritik der praktischen Vernunft, S. 210: „,Person] kommt [...] nur vernünftigen Wesen zu, welche für Gesetze und für Glück und Elend empfänglich sind. Diese Persönlichkeit erstreckt sich von der Gegenwart zurück in die Vergangenheit lediglich durch das Bewusstsein, wodurch es allein für vergangene Handlungen zurechnungsfähig wird und sie als seine eigenen aus demselben Grunde anerkennt, wie es dies für die gegenwärtigen thut." (zit. nach Weischedel, Werkausgabe Band VII, suhrkamp taschenbuch wissenschaft, 17. Aufl. 2014); s.a. Kant, Die Metaphysik der Sitten, S. 600 (zit. nach Weischedel, Werkausgabe Band VIII, suhrkamp taschenbuch wissenschaft, 22. Aufl. 2015).

178 Spindler, CR 2015, 766, 774.

179 BVerfG, Beschl. v. 02.05.1967, Az. 1 BvR 578/63, BVerfGE 21, 362, 369 - Sozialversicherungsträger.

180 So auch die Argumentation von Solaiman, Artificial Intelligence and Law 25 (2017), 155, 176; einschränkend Kersten, JZ 2015, 1, 7.

181 So auch Kersten, JZ 2015, 1, 7; Hanisch, in: Hilgendorf (Hrsg.), Robotik im Kontext von Recht und Moral, 2014, 27, 40; Schulz, Verantwortlichkeit bei autonom agierenden Systemen, 2015, S. 91 ff.; Schirmer, JZ 2016, 660, 663; vgl. für das Strafrecht Gleß/Weigend, ZStW 126 (2014), 561, 575.

${ }^{182}$ Differenzierend auch Kluge/Müller, DSRITB 2016, 989, 1004. 
generierte Willenserklärungen abgibt, in bestimmten Fällen (Teil-)Geschäftsfähigkeit einzuräumen. ${ }^{183}$ Bislang besteht jedoch schlicht kein Bedürfnis des Rechtsverkehrs danach, Kommunikations-KI für deliktsfähig zu erklären.

\section{Gefährdungshaftung}

Dem geltenden Recht näher ist die Überlegung, KI einer Gefährdungshaftung zu unterwerfen. ${ }^{184}$ Die Gefährdungshaftung betrifft erlaubtes, aber gefährliches Tun. ${ }^{185}$ Sie „beruht nicht auf Verantwortlichkeit für Unrecht, sondern auf dem Prinzip der Schadlosstellung für den Fall, daß sich ein Risiko verwirklicht, welches die Rechtsordnung zur Nutzung des technischen Fortschritts zuläßt. “186

Ökonomisch gewendet trägt der Schädiger bei einer Verschuldenshaftung nur die Kosten des Aufwandes der im Verkehr erforderlichen Sorgfalt. Kann er die Wahrung der Sorgfalt nachweisen (bzw. kann der Geschädigte eine Verletzung dieser Sorgfalt nicht nachweisen), trägt der Geschädigte die Kosten für den Schaden. Die Gefährdungshaftung hingegen internalisiert die Kosten sämtlicher Schäden zum Nachteil des Schädigers. Dieser bestimmt bei der Gefährdungshaftung seinen Sorgfaltsmaßstab selbst nach eigener Präferenz zwischen Kontrollaufwand und Haftungsrisiko, was im Ergebnis dazu führen kann, dass er von der gefährlichen Tätigkeit gänzlich absieht. ${ }^{187}$ Tatbestände der Gefährdungshaftung sehen deswegen regelmäßig eine Haftungsobergrenze vor ${ }^{188}$ und räumen QuasiExkulpationsmöglichkeiten für den Fall ein, dass der Verantwortliche die gefährliche Tätigkeit nach dem ,,Stand der Wissenschaft und Technik“ ausübte, ${ }^{189}$ um den Anreiz wieder zu erhöhen, die gefährliche - aber erlaubte und ggf. sogar sozial nützliche - Tätigkeit gleichwohl durchzuführen. In Ermangelung von Strafschadensersatz ist die

183 So etwa Wettig/Zehendner, Artificial Intelligence and Law 12 (2004), 111; Schirmer, JZ 2016, 660, 663 f.; Keßler, MMR 2017, 589, 592; Specht/Herold, MMR 2018, 40, 42; a.A. BGH, Urt. v. 16.10.2012, Az. X ZR 37/12, BGHZ 195, 126 Rn. 17 - Flugbuchung; Spindler, in: Hilgendorf (Hrsg.), Robotik im Kontext von Recht und Moral, 2014, 63, 64 f.; Schulz, Verantwortlichkeit bei autonom agierenden Systemen, 2015 , S. 102 ff. Instruktiv zum Vertragsschluss über Chatbots Franck/Müller-Peltzer, DSRITB 2017, 241, 246 ff.

184 So etwa Bräutigam/Klindt, NJW 2015, 1137, 1138 f.; Schirmer, JZ 2016, 660; Entschließung des Europäischen Parlaments vom 16. Februar 2017 mit Empfehlungen an die Kommission zu zivilrechtlichen Regelungen im Bereich Robotik (2015/2103(INL)), Tz. 59.

185 Z.B. Betrieb eines Kraftfahrzeugs ( $\$ 7$ StVG), Herstellen und Inverkehrbringen eines Produkts (§ 1 ProdHaftG), Betrieb einer Kernanlage ( $\$ 25$ AtomG), Inverkehrbringen von Arzneimitteln ( $\$ 84$ Abs. 1 AMG), Betrieb einer bestimmten Anlage ( 11 i.V.m. Anhang 1 UmweltHG).

186 BGH, Urt. v. 05.07.1988, Az. VI ZR 346/87, NJW 1988, 3019 - Streufahrzeug.

187 Vgl. Rohe, AcP 201 (2001), 117, 150 ff.

188 Siehe z.B. $\S 88$ AMG, $\S 15$ UmweltHG, $\S 10$ ProdHaftG; siehe aber auch $\S 31$ AtomG.

$189 \S 1$ Abs. 2 Nr. 5 ProdHaftG, $\S 26$ Abs. 4 Nr. 1 AtomG, $\S 84$ Abs. 1 Satz 2 AMG. 
Gefährdungshaftung die stärkste Ausprägung der regulatorischen Funktion des Deliktsrechts deutscher Prägung; die Einführung einer Gefährdungshaftung ist daher im Kern eine politische Entscheidung. Sie berührt die Grundfrage, welches Risiko eine Gesellschaft einzugehen bereit ist, um für den Nutzen einer Technologie die Gefahren durch diese Technologie hinzunehmen. Gefährdungshaftung bringt einen Gewinn an Sicherheit, ist aber zugleich innovationshemmend.

Das Hauptargument für die Einführung einer Gefährdungshaftung für KI ist praktischer Natur: Durch KI getroffene Entscheidungen sind nicht vorhersehbar und häufig im Nachhinein nicht mehr nachvollziehbar. ${ }^{190}$ Allerdings macht man es sich zu einfach, den Einsatz von KI per se als gefährlich anzusehen und damit der Gefährdungshaftung zu unterwerfen. ${ }^{191}$ Stattdessen ist wiederum nach den Einzelerscheinungen schwacher KI und den von ihnen ausgehenden Gefahren zu differenzieren. Bei Kommunikations-KI tritt zu der „Gefahrenquelle Mensch“ eine weitere Gefahrenquelle hinzu, nämlich die Maschine. Bei anderen KIs hingegen wird die Gefahrenquelle Mensch durch eine andere, vermeintlich intelligentere Gefahrenquelle ersetzt, etwa beim autonomen Fahren. ${ }^{192}$ Auch ist zu bedenken, dass von verschiedenen Formen Künstlicher Intelligenz verschiedene Gefahren ausgehen: Ein autonomes Kraftfahrzeug gefährdet potenziell Leib oder Leben, eine Kommunikations-KI hingegen „nur“ Persönlichkeitsrechte. Eine Gefährdungshaftung für Persönlichkeitsrechte würde daher mit der gesetzgeberischen Wertung brechen, Gefährdungshaftung grundsätzlich nur bei Delikten gegen Leib, Leben und Eigentum zu gewähren. ${ }^{193}$

Gegen Gefährdungshaftung für Kommunikations-KI spricht zudem, dass die Gefährdungshaftung ein ,geschlossenes System“194 ist: Einer Güterabwägung, wie sie das Allgemeine Persönlichkeitsrechts einfordert, ist sie nicht zugänglich. Das für die Gefährdungshaftung übliche Konzept der Haftungshöchstgrenzen, die die Haftungsrisiken begrenzen sollen, dürfte bei Persönlichkeitsrechtsverletzungen demgegenüber ohne Bedeutung sein. Die Persönlichkeitsrechtsverletzung beruht gerade darauf, dass ein

\footnotetext{
190 Vgl. Bräutigam/Klindt, NJW 2015, 1137, 1139; Reichwald/Pfisterer, CR 2016, 208, 212; Lohmann, ZRP 2017, 168, 169.

191 Zu pauschal daher: Entschließung des Europäischen Parlaments vom 16. Februar 2017 mit Empfehlungen an die Kommission zu zivilrechtlichen Regelungen im Bereich Robotik (2015/2103(INL)), Tz. 59; Schirmer, JZ 2016, 660, 665. Gegen eine Generalklausel der Gefährdungshaftung allgemein Rohe, AcP 201 (2001), 117, 158.

192 Horner/Kaulartz, CR 2016, 7, 13.

193 Siehe etwa $\S 1$ Abs. 1 Satz 1 ProdHaftG, § 26 Abs. 1 Satz 1 AtomG, $\S 84$ Abs. 1 Satz 1 AMG, 11 UmweltHG.

194 BGH, Urt. v. 05.07.1988, Az. VI ZR 346/87, NJW 1988, 3019 - Streufahrzeug.
} 
Individuum angegriffen wird. Bei sog. Kollektivbeleidigungen schwindet die persönliche Betroffenheit des einzelnen Mitglieds mit zunehmender Größe des Kollektivs. ${ }^{195}$ Schließlich ist zu bedenken, dass es bei Persönlichkeitsrechtsverletzungen in vielen Fällen auf den Nachweis eines Verschuldens, welches die Gefährdungshaftung entbehrlich macht, gar nicht ankommt. Unterlassung, Gegendarstellung und Widerruf setzen ein Verschulden nicht voraus. Die Einführung einer Gefährdungshaftung für Kommunikations-KI ist somit ebenfalls abzulehnen.

\section{Beweislastumkehr}

Die gegenwärtig bestehenden Zurechnungskonzepte des Deliktsrechts erweisen sich derzeit grundsätzlich als ausreichend, um den Entwicklungen der Kommunikations-KI juristisch Herr zu werden. Dies bedeutet nicht, dass kein Verbesserungsbedarf besteht. Allerdings bedarf der „Patient“ hierfür keiner großen „Operation“, etwa in Gestalt der Gefährdungshaftung. Eine weniger invasive rechtsmethodische Änderung im bestehenden System reicht aus, ist allerdings auch geboten.

Wie bereits dargestellt, besteht die größte praktische Herausforderung durch $\mathrm{KI}$ in der Beweissicherung und Nachvollziehbarkeit der Arbeit des Algorithmus. Daher fällt der Nachweis schwer, ob der Algorithmus auf eine Rechtsverletzung bereits angelegt war (algorithm bias) oder ob und wie die KI die streitgegenständliche Äußerung autonom und aufgrund eigenen „Lernens“ getroffen hat. Das wiederum ist entscheidend für die Frage, ob der Anbieter der KI seine Prüfungspflichten verletzt hat (siehe unter IV. 2. d) bis e)).

Mittlerweile beschäftigt sich ein ganzer Forschungszweig mit der Frage, wie man die Inputdaten, die für die Entscheidung des Algorithmus ausschlaggebend waren, ermittelt und unerklärbares Verhalten, sog. black boxes, vermeidet (sog. explainable artificial intelligence $(X A I))$. Das Problem besteht darin, dass das Verhalten eines autonom entscheidenden Algorithmus gerade nicht vorhersehbar ist. Die Operation des Algorithmus liegt jedoch ausschließlich in der Sphäre des Anbieters der KI. Aus diesem Grunde sollte eine Beweislastumkehr für Prüfungspflichtverletzung und Verschulden ${ }^{196}$ zugunsten des Geschädigten und zum Nachteil des Anbieters der KI greifen. Kann also der Geschädigte

195 Siehe BVerfG, Beschl. v. 10.10.1995, Az. 1 BvR 1476/91, 1 BvR 1980/91, 1 BvR 102/92, 1 BvR 221/92, NJW 1995, 3303, 3306 - „Soldaten sind Mörder“; BVerfG, Beschl. v. 17.05.2016, Az. 1 BvR 257/14, K\&R 2016, 494 Rn. 16 - „ACAB““.

196 In welchem Verhältnis Pflichtverletzung und Verschulden zueinander stehen, ist Gegenstand langjähriger Debatten (statt vieler Kötz/Wagner, Deliktsrecht, 13. Aufl. 2016, Rn. 106 ff., 128). An dieser Stelle braucht hierauf jedoch nicht näher eingegangen werden, denn sowohl die Pflichtverletzung als auch das Verschulen sollen Gegenstand der Beweislastumkehr sein. 
einen Eingriff in eines seiner Persönlichkeitsrechte nachweisen, so ist zu vermuten, dass dies auf einer verschuldeten Pflichtverletzung des Anbieters der KI beruht. Der Anbieter kann sich aber mit dem Nachweis der Wahrung seiner Prüfungspflichten exkulpieren.

Ratio für eine Beweislastumkehr ist die fehlende Aufklärungsmöglichkeit des Geschädigten, da die Pflichtverletzung in der Sphäre des Schädigers stattgefunden hat, der Schädiger also „,näher daran“ [ist], den Sachverhalt aufzuklären und die Folgen der Beweislosigkeit zu tragen."197 Dieses Diktum des BGH trifft auf Anbieter einer Kommunikations-KI in besonderem Maße zu. Zudem setzt eine Beweislastumkehr zu Lasten des Anbieters den Anreiz, die Aktivitäten seiner KI zu protokollieren und black boxes zu vermeiden. Die größte Rechtssicherheit entstünde, wenn der Gesetzgeber selbst die Beweislastumkehr festlegt. Denkbar wäre aber auch, dass Gerichte - etwa in analoger Anwendung von $\S 831$ Abs. 1 Satz 2 BGB - eine solche Beweislastumkehr begründen. ${ }^{198} \S 831$ Abs. 1 Satz 2 BGB liegt der Gedanke zugrunde, dass der Geschäftsherr aufgrund seiner Weisungshoheit die Möglichkeit hat, die Gefahr, die durch den Einsatz eines Dritten entsteht, zu beherrschen. ${ }^{199}$ Ergänzend ist erstrebenswert, den Anbietern von Kommunikations-KI Sorgfaltsmaßstäbe gemäß den „,anerkannten Regeln der Technik“, dem „Stand der Technik“ oder dem „Stand von Wissenschaft und Technik“ aufzuerlegen. ${ }^{200}$

\section{Schlussbemerkung}

Soweit ersichtlich, betraf der rechtswissenschaftliche Diskurs bislang nur die Frage, wie eine Haftung für KI auszugestalten ist. Zur Kontrolle der eigenen Überlegungen ist es jedoch stets hilfreich, gleichsam als advocatus diaboli einmal die entgegenstehende Position zu durchdenken: Was spricht dagegen, die zivilrechtliche Haftung für (Kommunikations-)KI gänzlich auszuschließen? Als Grund hierfür ließe sich anführen, dass Rechtsverletzungen durch KI (einschließlich Kommunikations-KI) Teil des allgemeinen Lebensrisikos sind und daher die Zurechnung ihrer „Handlungen“ zu einer natürlichen oder juristischen Person generell ausscheidet. Diese Überlegung scheint dem Rechtsempfinden so offenkundig zu widersprechen, dass zu überlegen ist, worin denn dieses Rechtsempfinden begründet ist. Die Antwort hierauf dürfte darin $\mathrm{zu}$ finden sein, dass $\mathrm{KI}$ in Deutschland - anders als

197 BGH, Urt. v. 26.11.1968, Az. VI ZR 212/66, NJW 1969, 269, 275 - Hühnerpest.

198 So Horner/Kaulartz, CR 2016, 7, 8; Keßler, MMR 2017, 589, 593; Denga, CR 2018, 69, 74 f. Für eine Übertragung des Rechtsgedankens des § 836 Abs. 1 Satz 2 BGB plädiert Grützmacher, CR 2016, 695, 698.

${ }^{199}$ Horner/Kaulartz, CR 2016, 7, 8.

${ }^{200}$ So Spindler, in: Hilgendorf (Hrsg.), Robotik im Kontext von Recht und Moral, 2014, 63 , 70 f.; Spindler, CR 2015, 766, 770 ff.; ihm folgend Denga, CR 2018, 69, 74. 
beispielsweise in Japan ${ }^{201}$ - noch nicht als allägliche Erscheinung wahrgenommen und ihr mit einer (nicht unbedingt ungesunden) Dosis Skepsis begegnet wird. Auch das Europäische Parlament konnotierte schon im ersten Absatz seiner Entschließung maschinelle Intelligenz negativ, indem es u.a. auf Mary Shelleys „Frankenstein“ und die Prager Legende vom Golem verwies. $^{202}$

Diese gesellschaftliche Einstellung und damit auch das Rechtsempfinden können sich freilich ändern. Ebenso wie noch vor 20 Jahren kaum vorstellbar war, wie freizügig heute mit persönlichen Daten umgegangen wird, lässt sich heute kaum ermessen, dass KI in 20 Jahren zum alltäglichen Leben gehören wird. Ist dies einmal der Fall, werden Fehler solcher Systeme möglicherweise als allgemeines Lebensrisiko eingestuft und eine Haftung entfiele. ${ }^{203}$

Dieses Gedankenspiel zeigt: Auch wenn viele technische Potenziale der KI noch Zukunftsmusik sind oder sich möglicherweise nie realisieren, sollte sich die Rechtswissenschaft bereits jetzt begleitend mit diesen Fragen beschäftigen, um nicht - wie dies etwa beim Datenschutz der Fall gewesen ist - von technologischen und gesellschaftlichen Entwicklungen vor vollendete Tatsachen gestellt zu werden. Hierfür bedarf es des Zusammenspiels verschiedener Teilrechtsgebiete, denen dabei jeweils eine eigene Funktion zukommt: die Ausgleichsfunktion des Deliktsrechts, Regulierung und Gefahrenabwehr durch das Medien-Aufsichtsrecht ${ }^{204}$ und das Strafrecht ${ }^{205}$ mit seiner Straffunktion. Zwar ist diese funktionelle Differenzierung ihrerseits zu überdenken; die Empfehlungen des Europäischen Parlaments oder auch der jüngst veröffentlichte Vorschlag der Europäischen Kommission zur Einführung einer Verbrauchersammelklage ${ }^{206}$ stehen stellvertretend für eine Neuorientierung des Deliktsrechts europäischer Prägung zu einem Instrument der Regulierung nach amerikanischem Vorbild. ${ }^{207} \mathrm{Um}$ den spezifischen

201 Aufschlussreich hierzu Wagner, Robotopia Nipponica: Recherchen zur Akzeptanz von Robotern in Japan, 2013; s.a. Nevejans, European Civil Law Rules in Robotics, Study for the JURI Committee, PE 571.379, 2016, S. 10; Denga, CR 2018, 69, 70.

202 Entschließung des Europäischen Parlaments vom 16. Februar 2017 mit Empfehlungen an die Kommission zu zivilrechtlichen Regelungen im Bereich Robotik (2015/2103(INL)), Tz. A.

203 Vgl. Gleß/Weigend, ZStW 126 (2014), 561, 587.

204 Dazu Dörr/Natt, ZUM 2014, 829; Drexl, ZUM 2017, 529.

${ }^{205}$ Dazu Ziemann, in: Hilgendorf/Günther (Hrsg.), Robotik und Gesetzgebung, 2013, 183; Joerden, in: Hilgendorf/Günther (Hrsg.), Robotik und Gesetzgebung, 2013, 195; Gleß/Weigend, ZStW 126 (2014), 561; Volkmann, MMR 2018, 58.

206 Proposal for a Directive of the European Parliament and of the Council on representative actions for the protection of the collective interests of consumers, and repealing Directive 2009/22/EC vom 11.04.2018 (COM(2018) 184 final).

${ }^{207}$ Zum regulatorischen Effekt des Deliktsrechts Rose-Ackerman, The American Economic Review 81 (1991), 54; speziell zu künstlicher Intelligenz Scherer, Harvard Journal of Law \& Technology 29 (2016), 353, 388 ff. 
Herausforderungen der Kommunikations-KI zu begegnen, ist das deutsche Deliktsrecht als ein Mosaikstein in einer austarierten Rechtsordnung für seinen Part bereits jetzt gut gerüstet. Zwar muss sich auch hier die Dogmatik weiterentwickeln; insbesondere bedarf es einer Beweislastumkehr für Pflichtverletzung und Verschulden. Im Hinblick auf KommunikationsKI ist die Aufregung des Europäischen Parlaments jedoch unbegründet.

Zum Deliktsrecht als Instrument der Regulierung Rohe, AcP 201 (2001), 117, 132 f.; Cane, Common Law World Review 31 (2002), 305; Poelzig, Normdurchsetzung durch Privatrecht, 2012, S. 57; Kendrick, Journal of Tort Law 10 (2017), 1. 